\title{
Toward a Taylor Rule for Fiscal Policy*
}

\author{
Martin Kliem ${ }^{\dagger}$ Alexander Kriwoluzky ${ }^{\ddagger}$ \\ Deutsche Bundesbank University of Bonn
}

December 13, 2011

\begin{abstract}
We determine and estimate the feedback variables for tax rates which capture the automatic stabilizing behavior of fiscal policy within a DSGE model. To that end we employ the working hypothesis that the fiscal feedback rules share similar characteristics with the Taylor-rule in monetary economics: the empirically observed rule itself is not optimal but its feedback variables are the choice of a welfare-maximizing policymaker. We determine investment for the tax rate on capital income and hours worked for the tax rate on labor income as most important from a normative point of view. What is more, we find strong empirical support for those feedback rules in comparison to common feedback rules in the literature.
\end{abstract}

JEL classification: E62, H30, C51.

Keywords: Fiscal policy, Bayesian model estimation, Identification

${ }^{*}$ We would like to thank Giancarlo Corsetti, Wouter denHaan, Dale Henderson, Mathias Hoffmann, Tatjana Kirsinova, Jenny Kragl, Michael Krause, Thomas Laubach, Bartosz Mackowiak, Alexander MeyerGohde, Tommaso Monacelli, Stephane Moyen, Gernot Müller, Morten Ravn, Christian Stoltenberg, Mathias Trabandt, Lutz Weinke, and Alexander Wolman for their helpful comments. Moreover, we would like to thank seminar participants and discussants at the Dynare Conference in Helsinki, the Canadian Economic Association in Quebec, the International Conference of the Society of Computational Economics in London, the Annual Congress of the European Economic Association in Oslo, the Verein für Socialpolik in Kiel, the University of Münster, the Bundesbank, and the ECB for their helpful comments. An earlier version of this paper was circulating under the title "Implementable Fiscal Policy Rules". The views expressed by the authors in this paper are their own and do not necessarily reflect those of the Deutsche Bundesbank.

${ }^{\dagger}$ Deutsche Bundesbank, Economic Research Center, Wilhelm-Epstein-Str. 14, 60431 Frankfurt am Main, Germany, email: martin.kliem@bundesbank.de, tel: +49699566 4759.

${ }^{\ddagger}$ University of Bonn, Department of Economics, Kaiserstrasse 7-9, 53113 Bonn, Germany, email: a.kriwoluzky@uni-bonn.de, tel: +49 2287362194. 


\section{Introduction}

In recent empirical work, Taylor (2000) and Auerbach (2002) provide evidence that there is an endogenous response of fiscal policy instruments to business cycles. In a dynamic stochastic general equilibrium (DSGE) model, the literature has started to model this endogenous response by policy feedback rules. So far, there is no agreement how these rules should be specified. For this reason, the rules are often modeled as simple ad-hoc processes (Leeper, Plante, and Traum, 2010a; Forni, Monteforte, and Sessa, 2009). These ad-hoc processes typically include output next to government debt as feedback variables. The choice of the latter is motivated to insure sustainability and determinacy of the economy. Additionally, its importance has been empirically documented. The choice of output as feedback variable is driven by the idea to capture the effects of automatic stabilizing policy. But, this is not founded on theoretical grounds and the empirical evidence by different studies is contradictory. In particular, recent studies mention that US Post-War data (Traum and Yang, 2011) as well as European data (Forni et al., 2009) are not informative to identify output or output growth in income tax rate feedback rules.

In this paper we determine and estimate the feedback coefficient that captures the automatic stabilizing effect. To that end we employ the working hypothesis that the fiscal feedback rules share similar characteristics with the Taylor-rule in monetary economics: the empirically observed rule itself is not optimal but its feedback variables are the choice of a welfare-maximizing policymaker. ${ }^{1}$ Consequently, we start by ascertaining those feedback variables that influence the tax rates at the optimal allocation most. Afterwards, we estimate the resulting policy coefficients to validate their empirical relevance. Thus, our aim is to provide evidence for a normative founded fiscal feedback coefficient to capture the contemporaneous business cycle effects. This ultimately implies a much more purposeful policymaker than typically assumed in standard DSGE models.

In contrast to the standard feedback rules, we find that different feedback variables should be employed for different policy instruments to capture the contemporaneous business cycle effects. For taxes on capital income this feedback variable is investment, for taxes on labor income it is hours worked. Both feedback variables are found to be most important to describe the dynamics of the each tax rate at the optimal allocation. Furthermore, we can identify these coefficients in the data and estimate the feedback coefficient on investment significantly different from zero. In comparison to feedback rules which contain output as feedback variable we find strong empirical support (75\% vs. $25 \%$ ) for the feedback rules specified in this paper.

The approach in this paper to determine fiscal feedback variables sidesteps pitfalls of alternative approaches. The standard approach to choose the variable to capture the automatic stabilizers ad-hoc is inconsistent with the typical assumptions for the remaining sectors in the economy, where their dynamic behavior is based on the solutions to their respective optimization problems. Hence households, firms, and the monetary policy authority act purposefully $^{2}$ while the fiscal policy sector does not. In that respect, characterizing a fiscal policy sector by ad-hoc rules constitutes a not at all satisfying approach. The procedure

\footnotetext{
${ }^{1}$ See e.g. Woodford (2003) for a discussion and evaluation of optimal feedback rules under commitment.

${ }^{2}$ Since the Taylor rule contains variables which are the correct choice of a welfare-maximizing policy maker, we classify monetary policy in common DSGE models as purposeful rather than ad-hoc.
} 
in this paper also avoids some inadequacies resulting from a social planner as a purposeful fiscal policy maker. This assumption involves very complex reaction functions. Additionally, for an empirical validation assuming an optimal policy maker is difficult to maintain. For instance, optimal fiscal policy in general implies subsidies for capital and the complex policy reaction functions are not identifiable. For that reason the policy maker's optimal behavior is approximated by simple feedback rules.

This paper adds to the recent literature in various ways. One strand of the literature investigates fiscal policy from a welfare-maximizing perspective. Benigno and Woodford (2006a) determine the optimal feedback variables in policy feedback rules. As shown in Benigno and Woodford (2006b), this approach delivers complex rules depending on a number of variables. For the sake of empirical relevance, in this paper we are interested in simple feedback rules rather than in a description of complete optimal policy (e.g. Kirsanova, Satchi, Vines, and Wren-Lewis, 2007). In particular, we select only those variables for the feedback rules which influence dynamics of the tax rates at the optimal allocation most.

Schmitt-Grohé and Uribe $(2004,2006)$ estimate feedback parameters of simple monetary and fiscal policy rules to mimic the dynamic behavior of the welfare-optimizing Ramsey planner. Moreover, Schmitt-Grohé and Uribe (2007) determine optimal and simple feedback rules by maximizing a second-order welfare approximation of the model. The setup of our work is closely related to these latter papers, but differs in two important aspects. First and foremost, we select the most important feedback variables to mimic the optimal dynamic behavior of the welfare-optimizing policymaker. The final simple linear rules are optimized with respect to their feedback variables rather than to their parameter loadings. Second, we use a full-fledged maximum likelihood estimation approach instead of the method of moments estimation or second-order welfare maximization when approximating the optimal policy rules with linear feedback rules. The additional information contained in the maximum likelihood approach makes it more efficient in terms of optimization and enables us to reach the position to start with a much larger and more agnostic policy rule.

Another strand of the literature has sought to empirically characterize fiscal feedback rules (e.g. Leeper et al., 2010a; Forni et al., 2009). Both studies include at least debt in the fiscal feedback rules. The motivation for this is that the inter-temporal government budget constraint has to be fulfilled under all circumstances. Empirical findings in the literature are a further motivation (e.g. Bohn, 1998). What is more, recent empirical work has tended to focus on the short-run cyclical behavior of fiscal policy (see Taylor, 2000; Auerbach, 2002; Favero and Monacelli, 2005). The intention behind this is to capture the recently increased activism of fiscal policy as mentioned by Auerbach (2002) as well as the observation that the "[...] overall size of the actual changes in taxes and spending due to the automatic stabilizers are frequently much larger than even the proposed discretionary changes. Both types of changes in taxes and spending impact aggregate demand, but the automatic ones are more predictable and work more quickly than the discretionary ones" (Taylor, 2000). Subsequently, the recent DSGE literature aims at characterizing automatic stabilizers in policy rules. For example, Jones (2002) assumes that fiscal policy responds to current and lagged output as well as hours worked and Leeper et al. (2010a) include output as an additional variable in the policy rules and consider potential correlations in the tax rates. In this paper, we rely on a normative approach instead an ad-hoc approach to derive simple fiscal feedback rules that characterize the fiscal policy authority operating in 
the model economy.

The remainder of the paper is organized as follows. Section 2 describes the model of the private sector and the monetary authority. The model is parameterized in Section 3. In Section 4 we present the methodology to determine the policy feedback variables. In Section 5 we investigate the empirical relevance of the policy feedback variables. Section 6 concludes.

\section{The Model}

In this section, we set up the economy, for which we derive the fiscal policy rules. We assume that the private sector as well as the monetary authority can be described by a conventional New Keynesian DSGE model. The model includes several real frictions: internal habit formation, capital utilization, and investment adjustment costs. It also comprises two nominal rigidities, one for wages and one for prices, both following the adjustment process postulated by Calvo (1983). The fiscal policy sector is modeled following Benigno and Woodford (2006b) with wasteful government spending and distortionary taxes on capital and wages but also lump-sum taxation. The model presented here, as in the succession of Christiano, Eichenbaum, and Evans (2005), and Smets and Wouters (2007), is designed to capture the behavior of the private sector well and is widely acknowledged as one of the workhorses in dynamic macroeconomics. It is close to the related literature, i.e. a model with which researchers have recently been aiming to replicate a fiscal policy sector. Since the model is well known, we keep the description brief and have moved First-order conditions to the appendix.

\subsection{Households and the labor market}

Throughout the model description, capital letters denote nominal variables and lower-case letters real variables. An exception is investment, which is always expressed in real terms as $I$.

In the economy, there exists a continuum of households indexed by $i \in[0,1]$. We assume homogeneity of the households with respect to consumption and asset holdings, but heterogeneity with respect to wages and hours worked in equilibrium. Therefore only labor services $l(i)$ provided by household $i$ and wages $w(i)$ are indexed by $i$. Consumption $c$, bond holdings $b$, and capital $k$ are not indexed. To ensure this property of the households in equilibrium, they receive the net cash flow from state-contingent securities $\iota$ (see e.g. Christiano et al., 2005).

Consumers' preferences are characterized by the discount factor $\beta$, the inverse of the intertemporal substitution elasticity $\sigma_{c}$, and the inverse of the labor supply elasticity with respect to wages $\sigma_{l}$. The parameter $h$ measures the internal habit persistence regarding consumption. Lifetime utility takes the following functional form:

$$
E_{t} \sum_{t=1}^{\infty} \beta^{t}\left[\frac{\left(c_{t}-h c_{t-1}\right)^{1-\sigma_{c}}}{1-\sigma_{c}}-\frac{l_{t}(i)^{1+\sigma_{l}}}{1+\sigma_{l}}\right]
$$


The intertemporal budget constraint of household $i$ is given by:

$$
\begin{aligned}
c_{t}+I_{t}+b_{t}= & \left(1-\tau_{t}^{w}\right) \frac{W_{t}(i)}{P_{t}} l_{t}(i)+\left(\left(1-\tau_{t}^{k}\right) r_{t}^{k} u_{t}-\phi_{t}\left(u_{t}\right)\right) k_{t-1} \\
& +\frac{\varepsilon_{q, t-1} R_{t-1} b_{t-1}}{\pi_{t}}+\left(1-\tau_{t}^{k}\right) d_{t}+\iota_{t}(i)+\tau_{t}^{L} .
\end{aligned}
$$

Wages $W$ are set according to a Calvo wage-setting scheme. The household invests $I$ into capital $k$. The rental rate on capital is denoted by $r^{k}$ and firms' dividends by $d$. The household pays lump-sum taxes (or receives transfers) $\tau^{L}$ as well as distortionary taxes $\tau^{w}$ and $\tau^{k}$ on labor income and capital income, respectively.

Households hold government bonds $b$ yielding return $R$. Government bonds are subject to a shock $\varepsilon_{q}$ that introduces a wedge between the interest rate controlled by the monetary authority and the government bonds. This risk premium shock follows a first order autoregressive process. ${ }^{3}$ The utilization rate of capital can be varied. The cost function of capacity utilization is denoted by $\phi(\cdot)$. Capital depreciates at a constant rate $\delta$. Investments are subject to a convex investment adjustment cost $s(\cdot)$. Capital accumulation is described by

$$
k_{t}=(1-\delta) k_{t-1}+\left[1-s_{t}\left(\frac{\varepsilon_{i, t} I_{t}}{I_{t-1}}\right)\right] I_{t} .
$$

where $\varepsilon_{i}$ denotes an investment-specific efficiency shock to the adjustment costs and is supposed to follow a first order autoregressive process. Households maximize lifetime utility (1) subject to the budget constraint (2) and the capital accumulation equation (3) with respect to $c, k, u, b$ and $I$. The resulting first-order conditions can be found in Appendix B.1.

Wage setting is modeled following Erceg, Henderson, and Levin (2000), i.e. analogously to staggered price setting. Each household supplies a differentiated type of labor service, $l(i)$, which is aggregated into a homogenous labor good by a representative competitive firm (labor packer). For any wage rate, each household supplies as many labor services as demanded. The labor packer aggregates according to a Dixit-Stiglitz aggregator with $\theta_{w}>1$ denoting the elasticity of substitution

$$
l_{t}^{d}=\left[\int_{0}^{1} l_{t}(i)^{\frac{\theta_{w}-1}{\theta_{w}}}\right]^{\frac{\theta_{w}}{\theta_{w}-1}} .
$$

Minimizing costs $W_{t} l_{t}^{d}$ and taking the individual wage costs of household $i, W_{t}(i)$, as given yields the demand for labor of type $i$.

In each period, household $i$ is allowed to set its wage with probability $1-\gamma_{w}$. If the household is not allowed to set its wage, wages are adjusted by the steady-state inflation rate of the economy $\bar{\pi}: W_{t}(i)=\bar{\pi} W_{t-1}$. Household $i$ chooses its optimal wage $W_{t}^{\star}=W_{t}(i)$

\footnotetext{
${ }^{3}$ The stochastic processes of all shock processes, the functional form of the cost of capacity utilization and the investment adjustment costs can be found in Appendix B.3.
} 
by maximizing the objective function

$$
\max _{W_{t}(i)} E_{t}\left[\sum_{k=0}^{\infty}\left(\gamma_{w} \beta\right)^{k}\left[\chi_{t+k} W_{t}(i) l_{t+k}(i)-U\left(l_{t+k}(i), c_{t+k}(i)\right)\right]\right] .
$$

The first-order condition to the maximization problem (5) and the resulting law of motion for $w_{t}^{*}$ are given in Appendix B.1.

\subsection{Firm sector}

The economy consists of two firm sectors. In one sector, perfectly competitive firms produce the final good $y$ using as inputs intermediate goods $y(j)$ produced by monopolistically competitive firms indexed by $j$. Final-goods firms have access to the constant-returns-to-scale production function with elasticity of substitution $\theta_{p}$

$$
y_{t}=\left[\int_{0}^{1} y_{t}(j)^{\frac{\theta_{p}-1}{\theta_{p}}}\right]^{\frac{\theta_{p}}{\theta_{p}-1}} .
$$

Cost minimization yields the demand for each intermediate good $y(j)$ and the corresponding price index, which are provided in Appendix B.2.

The intermediate goods are produced by a continuum of monopolistically competitive firms $j \in[0,1]$ using the production function

$$
y_{t}(j)=\left(u_{t} k_{t-1}(j)\right)^{\alpha}\left(l_{t}^{d}(j) \varepsilon_{z, t}\right)^{1-\alpha}-\Omega,
$$

where $\alpha$ denotes the output elasticity with respect to capital and $\Omega$ fixed costs of production. The variable $\varepsilon_{z}$ represents a labor-augmenting productivity shock assumed to follow a first order autoregressive process. Intermediate-good firms maximize profits:

$$
\max _{\left(u_{t} \cdot k_{t-1}(j)\right), l_{t}^{d}(j)}\left[\left[\frac{P_{t}(j)}{P_{t}}\right]^{-\theta_{p}}\left(y_{t}(j)-w_{t} l_{t}^{d}(j)-r_{t}^{k} u_{t} k_{t-1}(j)\right)\right]
$$

The first-order conditions of (8) are given in the Appendix B.2.

Intermediate-good firms are subject to staggered price setting, i.e. they are allowed to adjust their prices with probability $\left(1-\gamma_{p}\right)$. Prices of firms which cannot re-optimize evolve according to $P_{t}(j)=\bar{\pi} P_{t-1}$. Price-resetting firms choose $P_{t}^{\star}=P_{t}(j)$ to maximize the expected sum of discounted future profits:

$$
\max _{P_{t}(j)} \quad E_{t} \sum_{k=0}^{\infty} \gamma_{p}^{k} m_{t+k}\left[P_{t}(j) y_{t+k}(j)-Z_{t+k} y_{t+k}(j)\right]
$$

where future profits are discounted by the stochastic discount factor $m_{t+k}=\beta^{j} \frac{\chi_{t+j} P_{t}}{\chi_{t} P_{t+j}}$ and $Z$ denotes nominal marginal costs. The first-order condition to the maximization problem (9) and the resulting law of motion for $p_{t}^{*}$ are given in Appendix B.2. 


\subsection{Government sector and Aggregation}

The monetary authority sets nominal interest rates according to a Taylor rule that includes lagged nominal interest rates, lagged output, current inflation, and an i.i.d. monetary policy shock $\epsilon^{m}$ :

$$
\log \left(\frac{R_{t}}{\bar{R}}\right)=\rho_{R} \log \left(\frac{R_{t-1}}{\bar{R}}\right)+\left(1-\rho_{R}\right)\left(\rho_{\pi} \log \left(\frac{\pi_{t}}{\bar{\pi}}\right)+\rho_{y} \log \left(\frac{y_{t}}{\bar{y}}\right)\right)+\epsilon_{t}^{m}
$$

The fiscal authority receives tax revenues $x$ and issues bonds $b$ to finance government consumption expenditure $c^{g}$. The government budget constraint therefore reads as:

$$
\left[b_{t}-\frac{b_{t-1} \varepsilon_{q, t-1} R_{t-1}}{\pi_{t}}\right]=c_{t}^{g}-x_{t}-\tau_{t}^{L}
$$

Government tax revenues consist of taxes on wages and capital:

$$
x_{t}=\tau_{t}^{w} w_{t} l_{t}+\tau_{t}^{k}\left[r_{t}^{k} u_{t} k_{t-1}+d_{t}\right]
$$

Government consumption expenditures and lump-sum taxes evolve according to exogenous first order autoregressive processes.

This paper's analysis focuses on policy feedback rules for taxes on capital income and labor income. We assume the tax rates are given by policy feedback rules, which are functions of the model's variables, $X_{t}^{z}$, policy feedback parameters, $\theta^{P}$, and corresponding i.i.d. error terms, $\epsilon_{t, \tau^{w}}$ and $\epsilon_{t, \tau^{k}}$ :

$$
\begin{aligned}
\tau_{t}^{w} & =f\left(X_{t}^{z}, \epsilon_{t, \tau^{w}}, \theta^{P}\right), \\
\tau_{t}^{k} & =f\left(X_{t}^{z}, \epsilon_{t, \tau^{k}}, \theta^{P}\right),
\end{aligned}
$$

The formulation of sticky prices and wages implies inefficiencies and output losses relative to an economy with flexible prices in the goods and labor market. Since we are interested in the optimal allocation of this economy, we have to take the effects of price and wage dispersion into account when aggregating across firms and households (e.g. Schmitt-Grohé and Uribe, 2006). We follow Schmitt-Grohé and Uribe (2006) and define the variable $p_{t}^{+}$to capture the resource costs induced by inefficient price dispersion, and the variable $w_{t}^{+}$to take the loss in output caused by wage dispersion into account. The dispersion of wages causes a dispersion in utility across households. This dispersion is measured by the variable $\tilde{w}_{t}^{+}$.

The formal definitions of $p_{t}^{+}, w_{t}^{+}, \tilde{w}_{t}^{+}$, the aggregated utility across households, the resource constraint of the economy as well as all equations necessary to reproduce the aggregation of the economy are given in Appendix B.4.

\section{Parametrization of the Model}

To parameterize the private sector behavior and the monetary authority we estimate the model using Bayesian estimation methods. 


\subsection{Data}

As observable variables we employ private consumption, private investment, output, inflation, tax rates on capital and wages, public transfers, interest rates, and tax revenues. Since the model is not thought of as giving a precise description of tax revenues, we add a measurement error to the tax revenue observation equation. This leaves us with eight structural shocks incorporated in the model, and one additional measurement error, which correspond to the nine observable variables.

The time series are quarterly US data. A detailed description of the source can be found in appendix A. The tax rates are computed as in Jones (2002). Whenever necessary, the data are transformed into real terms and per capita.

Since the employed model does not exhibit an endogenous trend, we de-trend the data prior to the estimation. In contrast to most studies in the literature, we do not use a firstdifference filter to de-trend the data, because it puts too much weight on high frequencies of the data. Instead, we employ a one-sided HP filter. ${ }^{4}$ In contrast to the two-sided HP filter, the one-sided HP filter is not adversely affected by the correlation of data points with subsequent observations. The one-sided HP filter is implemented for each time series using an initialization window of 40 quarters.

The complete data set ranges from 1958:1 to 2009:2. For the estimation procedure we employ only a sub-sample covering 1983:1 to 2008:4. We choose this particular sample for two reasons: first, to exclude the high-inflation period during the 1970s and the Volcker disinflation years, and second, because monetary policy is characterized by a Taylor rule (Taylor, 1993) and thought to be active, whereas fiscal policy is assumed to be passive (in the spirit of Leeper, 1991). All of these assumptions are included in our model setup and by the subsequent prior choice.

\subsection{Estimation and Calibrated Parameters}

We set the steady-state quarterly nominal interest rate of $1.0133 \%$ to match the average trend in our dataset. The discount factor $\beta=0.993$ is set to match the average annual trend inflation $(2.51 \%)$. In order to match an investment-to-output ratio of $20 \%$, we set the share of capital in production to $\alpha=0.4$ and the depreciation rate of capital to $\delta=0.025$. Similarly to Schmitt-Grohé and Uribe (2004), the elasticities of substitution between intermediate goods $\theta_{p}$ and labor inputs $\theta_{w}$ are chosen so that the steady-state mark-up for prices and wages is $20 \%$ and $10 \%$, respectively.

The steady-state ratio of government consumption expenditures to output $\bar{c}^{g} / \bar{y}$ and the steady-state ratio of lump-sum taxes to output $\bar{\tau}^{L} / \bar{y}$ are set to $19 \%$ and $-8 \%$, respectively. This implies a annual ratio of the debt-to-output ratio of approximately $48 \%$. The steadystate values for the tax rates on capital $\bar{\tau}^{k}=0.3572$ and wages $\bar{\tau}^{w}=0.2343$ are the averages of our time series. ${ }^{5}$

The remaining parameters are estimated. In general, we follow the most recent and widely accepted studies for our choice of the prior distributions (see e.g. Smets and Wouters,

\footnotetext{
${ }^{4}$ The filter is parameterized with $\lambda_{H P}=1600$.

${ }^{5}$ See Trabandt and Uhlig (2011) for similar assumptions about tax rates, government consumption, and government transfers.
} 
2007; Christiano, Motto, and Rostagno, 2010; Altig, Christiano, Eichenbaum, and Lindé, 2010). In some cases, we deviate from that literature to allow for a slightly wider and less informative prior distribution.

In order to parameterize the private sector we have to specify the fiscal policy in more detail to close the model. For this reason we choose the following simple fiscal feedback rules:

$$
\begin{aligned}
& \log \left(\frac{\tau_{t}^{w}}{\bar{\tau}^{w}}\right)=\rho_{w} \log \tau_{t-1}^{w}+\left(1-\rho_{w}\right)\left[\eta_{w b} \log \left(\frac{b_{t-1}}{\bar{b}}\right)+\eta_{w y} \log \left(\frac{y_{t}}{\bar{y}}\right)\right]+\epsilon_{t, \tau^{w}}, \\
& \log \left(\frac{\tau_{t}^{k}}{\bar{\tau}^{k}}\right)=\rho_{k} \log \tau_{t-1}^{k}+\left(1-\rho_{k}\right)\left[\eta_{k b} \log \left(\frac{b_{t-1}}{\bar{b}}\right)+\eta_{k y} \log \left(\frac{y_{t}}{\bar{y}}\right)\right]+\epsilon_{t, \tau^{k}},
\end{aligned}
$$

where $\epsilon_{t, \tau^{w}}$ and $\epsilon_{t, \tau^{k}}$ denote i.i.d. error terms. Both instruments respond to lagged government debt to ensure fiscal solvency. Moreover, to capture the role of income taxes as automatic stabilizers, both feedback rules are allowed to respond to output contemporaneously. This assumption can also be found in other recent studies like Leeper et al. (2010a), Traum and Yang (2010), Leeper, Richter, and Walker (2010b), and Fernández-Villaverde, Guerrón-Quintana, Kuester, and Rubio-Ramírez (2011). We choose a prior distribution for the parameters similar to the existing literature: The autoregressive coefficients are assumed to be Beta-distributed with mean 0.85 and a standard deviation of 0.1 and the coefficients on government debt are Gamma-distributed with mean 0.4 and a standard deviation of 0.2. The latter assumption ensures fiscal solvency as well as that fiscal policy acts passive.

For the automatic stabilizers it is often a Gamma distribution as prior distribution assumed which is strictly positive. We deviate from the standard prior choice for the following reasoning. The choice of the Gamma distribution is motivated by the estimation results of Blanchard and Perotti (2002) which suggest a positive elasticity between tax revenues and output implying also a positive elasticity of the total households' average tax rate with output. But, this does not imply that each tax instrument faces a positive elasticity with output. Therefore, we use a less restrictive and more diffuse prior which is assumed to be Normal-distributed with mean 0 and a standard deviation of 0.5 .

To estimate the parameters, we estimate the posterior mode of the distribution and employ a random walk Metropolis-Hastings algorithm to approximate the distribution around the posterior mode. We run two chains, each with 1,000,000 parameter vector draws. The first $90 \%$ have been discarded. ${ }^{6}$

The prior and posterior distributions are plotted in Figures C-6, C-7, and C-8. The results indicate that the posterior distributions of all structural parameters are well approximated around the posterior mode. Furthermore, the results also show that all parameters, except the inverse of the Frisch elasticity, $\sigma_{l}$, are identified as being substantially different from their prior distribution. ${ }^{7}$ Table 1 provides detailed posterior statistics, e.g. posterior mean and the HPD interval of $10 \%$ and $90 \%$, for the estimates feedback parameters of the fiscal feedback rules. ${ }^{8}$

\footnotetext{
${ }^{6}$ Convergence statistics and further diagnostics are provided in the technical appendix on our websites, e.g. http : //www.mwpweb.eu/AlexanderKriwoluzky/research_current_projects.html.

${ }^{7}$ The difficulty in identifying the inverse of the Frisch elasticity, $\sigma_{l}$, stems from our choice of the observable variables, which leads to a rather flat likelihood as indicated by the check plots in the technical appendix.

${ }^{8}$ The posterior distributions of the remaining parameters fit into those obtained by the literature (see e.g.
} 


\begin{tabular}{lccccc}
\hline \hline Parameter & Symbol & Mode & Mean & $10 \%$ & $90 \%$ \\
\hline Labor tax AR coefficient & $\rho_{w}$ & 0.8577 & 0.8586 & 0.7842 & 0.9405 \\
Labor tax debt coefficient & $\eta_{w b}$ & 0.2887 & 0.3406 & 0.1003 & 0.5574 \\
Labor tax output coefficient & $\eta_{w y}$ & 0.1106 & 0.0883 & -0.6154 & 0.7909 \\
Capital tax AR coefficient & $\rho_{k}$ & 0.8162 & 0.8219 & 0.7410 & 0.9045 \\
Capital tax debt coefficient & $\eta_{k b}$ & 0.2565 & 0.2915 & 0.0819 & 0.4891 \\
Capital tax output coefficient & $\eta_{k y}$ & 0.5257 & 0.5035 & -0.1822 & 1.1866 \\
\hline \hline
\end{tabular}

Table 1: Posterior mode and posterior distribution of the benchmark model's fiscal feedback parameters.

Figure 1 shows the posterior and prior distributions for all feedback parameters of each of the fiscal rule. The autoregressive parameters and the feedback coefficients on debt in each tax rule are estimated differently from the prior distribution. In contrast to these coefficients the feedback coefficient on output in the feedback rule for labor income taxes is not identified. In the feedback rule for capital income tax rates the feedback coefficient on output is identified, but is not estimated significantly different from zero. This finding corresponds to the experiences reported by Forni et al. (2009, p. 565) for European data. The authors find in general positive but not significant feedback parameters on the growth rate of output in the feedback rules. Similarly, Traum and Yang (2011) mention that U.S. Post-War data are not informative about a feedback parameter for contemporaneous output in the income tax rates.
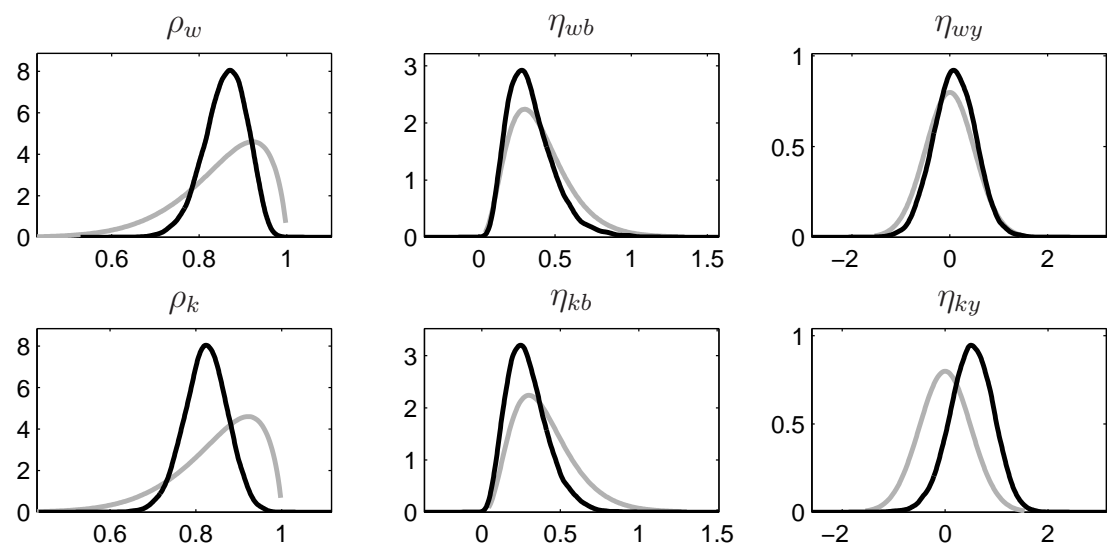

Figure 1: Prior (grey dashed) and posterior (black solid) distribution of policy feedback parameters.

Summarizing this subsection, we find that our estimation results for the parameters describing the private sector are well identified therefore represent a good description of the

Smets and Wouters, 2007), details can be found in table C in appendix C. 
private sector of the economy and a good starting point for the subsequent identification of fiscal policy rules.

\section{Determination of Fiscal Policy Rules}

In this section we determine the feedback variables which should be included into the feedback rules. To that end, we compute the optimal allocation given the posterior estimates of the model's private sector. Section 4.2 summarizes the approximation of the optimal policy problem's highly non-linear solution with simple and linear rules. In Section 4.3, we describe the calculation of the elasticities of tax rates with respect to the feedback coefficients and select the variables for the extended rules.

\subsection{Optimal Policy}

Given the structural estimates, we compute the optimal equilibrium of the economy described in Section 2. We assume that the government has operated for an infinite number of periods and honors the commitments it has made in the past. This kind of policy under commitment is optimal from a timeless perspective (Woodford, 2003). The benevolent policymaker has two instruments, taxes on labor income and taxes on capital income.

Let $N$ be the number of endogenous variables and number of policy instruments is two. ${ }^{9}$ Then, the optimal policy problem is defined as maximizing the life time expected utility subject to $(N-2)$ equations which describe the model economy laid out in section 2 . The complete setup of the maximization including a detailed list of the relevant constraints and the definition of the optimal equilibrium can be found in Appendix B.5.

When we compute the optimal policy, we solve for steady-state values of $\tau^{k}$ and $\tau^{w}$, which solve the first-order conditions of the policymaker's maximization problem. The steadystates of the tax rates are $\bar{\tau}_{k}=-0.1044$ and $\bar{\tau}_{w}=0.5330$. The implied debt-to-output ratio is $\frac{\bar{b}}{\bar{y}}=0.6405$. The steady state values of the tax rates are in line with the values computed by Schmitt-Grohé and Uribe (2006). As in their approach, the social planner faces the following trade-off when setting the optimal tax rate for capital income and profits. On the one hand, she aims at eliminating the distortion between private and social returns on capital stemming from the price mark-up with a negative tax rate (see Judd, 2002). On the other hand, the social planner has an incentive to tax the profits with a high income tax. In the present model, the two opposite effects lead to a negative tax rate on capital and profits. To finance this subsidy and the given level of government consumption expenditures and transfers, the policymaker has to increase the tax rate on labor income.

\subsection{Approximation of Optimal Policy Rules by Linear Rules}

In this section we describe the construction of the simple and linear rules for an approximation of the optimal policy.

Denote the set of variables the policymaker is interested in, or observable variables, by $X^{o}$. The observable variables are linked to the endogenous state variables $X^{z}$ via the observation

\footnotetext{
${ }^{9}$ In our benchmark model the number of endogenous variables is $N=30$.
} 
equation

$$
X_{t}^{o}=H X_{t}^{z}
$$

The state variables evolve according to the state equation, which is the log-linearized solution of the model described in Section 2

$$
X_{t}^{z}=T\left(\theta^{M}\right) X_{t-1}^{z}+R\left(\theta^{M}\right) X_{t}^{\epsilon},
$$

where $\theta^{M}$ is a vector collecting the structural parameters of the model and $X^{\epsilon}$ the exogenous variables. We partition the vector into two sub-vectors: $\theta^{M}=\left[\theta^{S} \theta^{P}\right]$. The vector $\theta^{S}$ contains all the structural model parameters which are not included in the fiscal policy rules. The coefficients of the fiscal policy rules are included in the vector $\theta^{P}$. In the benchmark model, the policy rules have been assumed to be eq. (13) and (14). Here, we define two very extensive rules, including a large variety of macroeconomic variables:

$$
\begin{aligned}
\tau_{t}^{w} & =f\left(b_{t-1}, k_{t-1}, y_{t}, c_{t}, l_{t}, w_{t}, I_{t}, \pi_{t}, R_{t}\right) \text { and } \\
\tau_{t}^{k} & =f\left(b_{t-1}, k_{t-1}, y_{t}, c_{t}, l_{t}, w_{t}, I_{t}, \pi_{t}, R_{t}\right)
\end{aligned}
$$

The vector of corresponding policy coefficients is

$$
\begin{gathered}
\theta^{P}=\left[\eta_{w k}, \eta_{w b}, \eta_{w y}, \eta_{w c}, \eta_{w l}, \eta_{w I}, \eta_{w \pi}, \eta_{w w}, \eta_{w R}\right. \\
\left.\eta_{k k}, \eta_{k b}, \eta_{k y}, \eta_{k c}, \eta_{k l}, \eta_{k I}, \eta_{k \pi}, \eta_{k w}, \eta_{k R}\right]
\end{gathered}
$$

where the two subscripts denote the tax instrument and their partial elasticities with respect to the feedback variables, respectively. To estimate $\theta^{P}$, we fix $\theta^{S}$ at its posterior mode (see Section 3.2). Given the optimal allocation derived in Section 4.1, we simulate artificial time series. More precisely, we simulate data at the optimal allocation given a sequence of disturbances $\left(\epsilon_{i}, \epsilon_{z}, \epsilon_{m}, \epsilon_{q}, \epsilon_{c g}\right)$. We assume that the disturbances have the same volatility as estimated before. We do not include the transfer shock into the simulation because it accounts for less than one percent of the variation in any of the variables in the subsequent analysis.

We use the simulated data for taxes on labor income and capital income as observable variable $\left(X_{t}^{o}=\left[\begin{array}{ll}\tau_{t}^{w} & \tau_{t}^{k}\end{array}\right]^{\prime}\right)$ to estimate the state system consisting of (18) and (17) using Bayesian model estimation.

In order to assure that the implied volatilities by the model closed with the simple feedback rules are in line with the volatilities of the artificial data we form the priors for the feedback coefficients endogenously. In our specification we follow a method recently proposed by Christiano, Trabandt, and Walentin (2011). ${ }^{10}$ As an initial set of priors we define for all feedback coefficients a diffuse prior distribution, namely a Normal distribution with mean zero and a standard deviation of 1 . A more detailed description of this approach as well as detailed properties of the endogenous priors can be found in the corresponding appendix of Christiano et al. (2011).

The estimation results can be found in Table 2. As a next step, we check whether the

\footnotetext{
${ }^{10}$ For an alternative approach to form endogenous priors for DSGE models see Del Negro and Schorfheide (2008).
} 


\begin{tabular}{|c|c|c|c|c|}
\hline Feedback Parameter & Symbol & Mode & S.d. & T-value \\
\hline \multicolumn{5}{|c|}{ TAX RATE on Labor InCOME } \\
\hline Capital & $\eta_{w k}$ & -1.4772 & 0.5126 & 2.8818 \\
\hline Debt & $\eta_{w b}$ & 0.2112 & 0.1415 & 1.4928 \\
\hline Output & $\eta_{w y}$ & -0.1777 & 0.9059 & 0.1961 \\
\hline Consumption & $\eta_{w c}$ & 0.2126 & 0.6268 & 0.3391 \\
\hline Hours worked & $\eta_{w h}$ & -2.7104 & 0.4252 & 6.3742 \\
\hline Wage rate & $\eta_{w w}$ & 0.4919 & 0.5868 & 0.8382 \\
\hline Investment & $\eta_{w I}$ & 0.4434 & 0.3831 & 1.1575 \\
\hline Inflation & $\eta_{w \pi}$ & -0.6810 & 0.9110 & 0.7475 \\
\hline Nominal interest rate & $\eta_{w R}$ & -0.2868 & 0.9594 & 0.2990 \\
\hline \multicolumn{5}{|c|}{ Tax Rate on Capital InCOME } \\
\hline Capital & $\eta_{k k}$ & -0.8649 & 0.9839 & 0.8790 \\
\hline Debt & $\eta_{k b}$ & -4.0821 & 0.9201 & 4.4365 \\
\hline Output & $\eta_{k y}$ & 2.7774 & 0.9440 & 2.9422 \\
\hline Consumption & $\eta_{k c}$ & 0.4917 & 1.0270 & 0.4788 \\
\hline Hours worked & $\eta_{k h}$ & 1.9896 & 0.8723 & 2.2807 \\
\hline Wage rate & $\eta_{k w}$ & 0.1517 & 0.9738 & 0.1558 \\
\hline Investment & $\eta_{k I}$ & 4.6741 & 0.5581 & 8.3745 \\
\hline Inflation & $\eta_{k \pi}$ & 0.2272 & 1.0050 & 0.2261 \\
\hline Nominal interest rate & $\eta_{k R}$ & -0.3189 & 1.0048 & 0.3174 \\
\hline
\end{tabular}

Table 2: Posterior mode maximization of optimized feedback coefficients.

simple linear rules are indeed a good approximation of the optimal policy rules. To that end we compare the implied smoothed time series of the linear tax rules with the time series generated at the optimal allocation. The smoothed variables are generated by applying the same sequence of shocks to the Ramsey policy model as well as to the model closed with optimized rules. The comparison is plotted in Figure 2. The plots indicate that the simple rules approximate the optimal policy rules satisfactorily.

In the succeeding step, the estimated posterior distributions of the feedback parameters are employed to determine those feedback coefficients that have the most impact on the dynamics at the optimal allocation.

\subsection{Computation of the Elasticities}

We calculate the elasticities of the variance of the variables of interest with respect to the feedback coefficients employing the methodology proposed by Iskrev (2010). The variables of interest comprise the two tax rates and as an additional informative variable welfare. ${ }^{11}$

${ }^{11}$ Welfare is defined as $\mathcal{W}_{t}=U_{t}+\beta \mathcal{W}_{t+1}$. 
Output
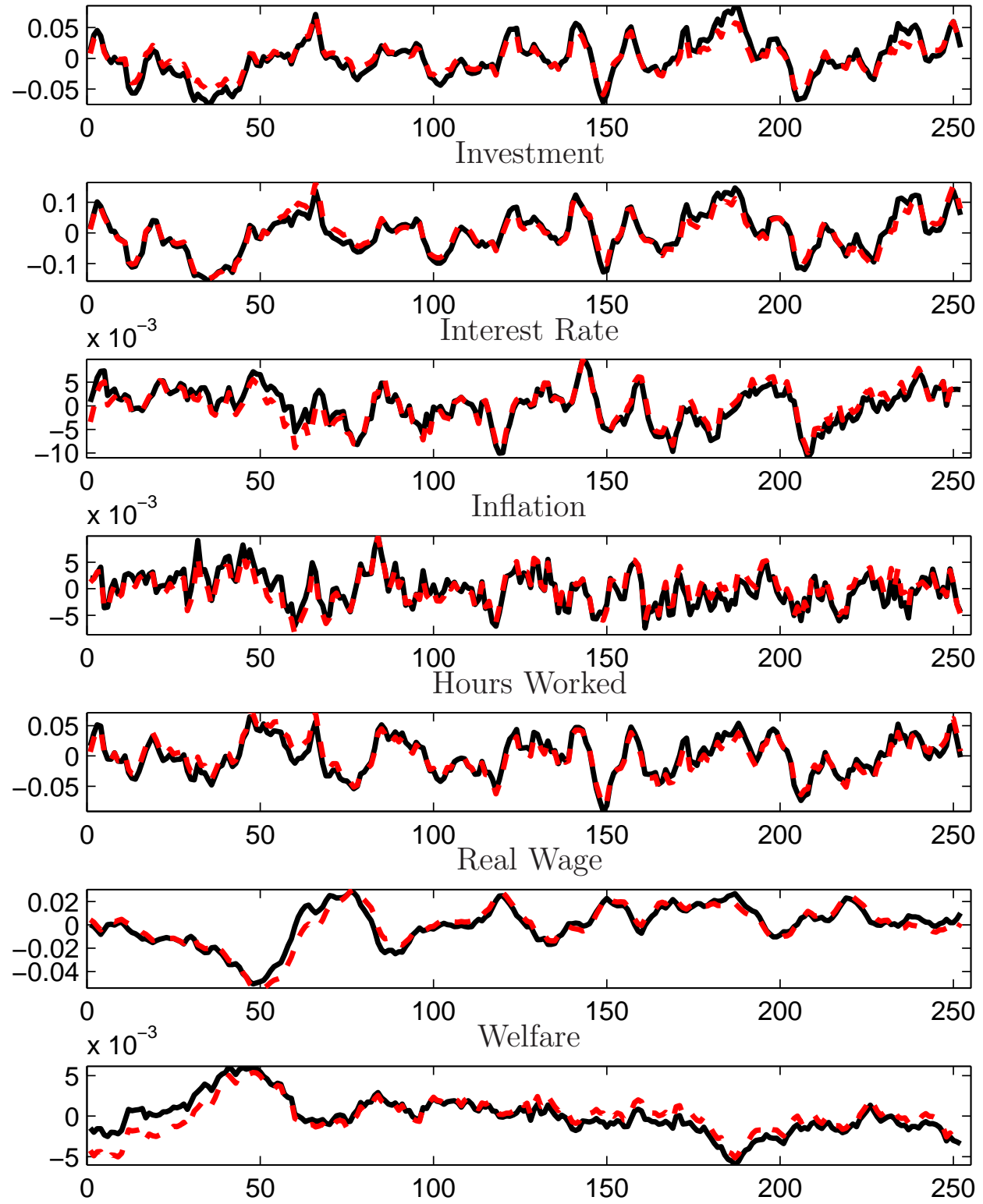

\section{— Optimized Rules - - - Optimal Policy}

Figure 2: Smoothed variables under optimized rules (solid) and optimal policy (dashed) 
The vector of observables is thus expanded $X_{t}^{O}=\left[\begin{array}{lll}\tau_{t}^{k} & \tau_{t}^{w} & \mathcal{W}_{t}\end{array}\right]^{\prime}$.

The second moments ${ }^{12}$ of a set of observable variables $X^{o}$ are the variance-covariance matrix $\Sigma_{X^{o}, 0}$ and $l$ autocovariances $\left(\Sigma_{X^{o}, 1}, \ldots \Sigma_{X^{o}, l}\right)$, which can be summarized in the vector $\Sigma_{X^{o}, L}$ :

$$
\Sigma_{X^{o}, L}=\left[\operatorname{vech}\left(\Sigma_{X^{o}, 0}\right)^{\prime}, \operatorname{vec}\left(\Sigma_{X^{o}, 1}\right)^{\prime} \ldots \operatorname{vec}\left(\Sigma_{X^{o}, l}\right)^{\prime}\right]^{\prime} .
$$

The moments $\Sigma_{X^{o}, L}$ are calculated from the state space system defined by equations (18) and (17). The matrices $T$ and $R$ contain non-linear combinations of the structural parameter vector $\theta^{M}$. In order to take into account the dependence of the moments $\left(\Sigma_{X^{o}, L}\right)$ on the recursive law of motion which itself depends on structural parameters $\left(\theta^{M}\right)$, the Jacobian $J(L)$ is decomposed into two Jacobians

$$
J(L)=J_{1} J_{2}
$$

where $J_{1}$ contains the partial derivatives of the moments $\Sigma_{X^{o}, L}$ with respect to each recursive law of motion, and $J_{2}$ the partial derivatives of each recursive law of motion with respect to each parameter. Since we fix $\theta^{S}$, we compute partial derivatives with respect to the 18 policy coefficients in $\theta^{P}$ only. We set $L=0$, i.e. we consider the variances only, and use DYNARE to compute the Jacobian $J(L)$. Afterwards, we multiply the partial derivatives by the policy coefficients and divide them by the corresponding moment to calculate the elasticities. To quantify the uncertainty, we take 10000 draws from the distribution of the policy coefficients derived in Section 4.2. The results are plotted in Figures 3 and 4. These figures display the box plot of the $75 \%$ quantile of the elasticities with respect to each policy coefficient normalized by the largest elasticity. ${ }^{13}$

Inspecting the Figure 3, the most important variable to influence the variance of the labor income tax rate is hours worked. This result is stressed by the importance of hours worked for welfare's variance. Figure 4 shows that investment is the most important feedback variable for the variance of taxes on capital income as well as welfare's variance. Thus, for different policy instruments, different feedback variables are important. This result is in line with Benigno and Woodford (2006a), who find that optimal rules for taxes on capital income and labor income should respond to different feedback variables in their model. Since the coefficient on hours worked in the rule for labor income taxes as well as the coefficient on investment in the rule for capital income taxes are clearly distinguishable from the other feedback variables, we choose them as candidates in our tax rules.

\section{Empirical Evidence}

This section investigates whether the data are informative about the variables which are important from a normative point of view. For this reason we estimate the model employing a capital income tax rate which responds contemporaneous on investment and a labor income tax rate which responds contemporaneous on hours worked instead of the rules (13) and (14).

\footnotetext{
${ }^{12}$ While the methodology proposed in Iskrev (2010) also includes first moments of the data, we only consider second moments in our estimation. The steady state of the model simulating the data and the estimated model are identical.

${ }^{13}$ Tables $\mathrm{C}-7$ and $\mathrm{C}-8$ in Appendix C provide more detailed results.
} 

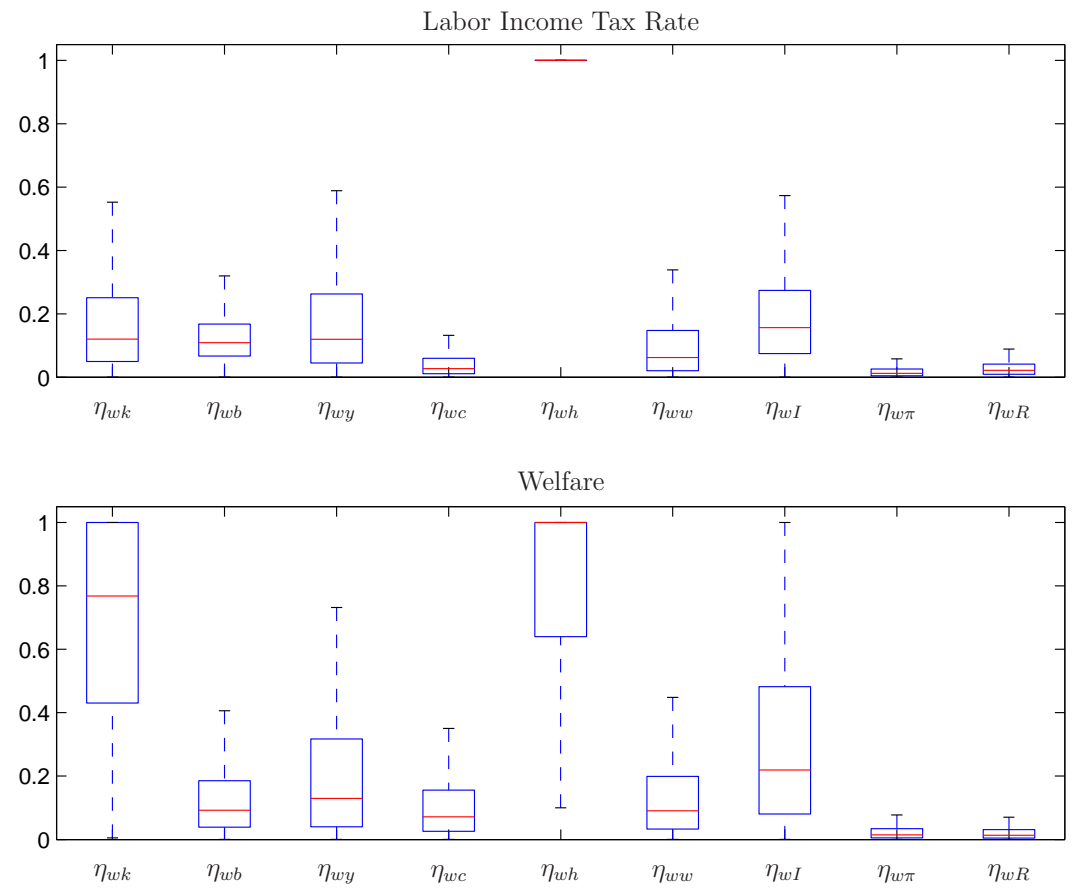

Figure 3: Relative elasticity of variables' variance w.r.t. feedback parameters of the labor income tax rule.

The new feedback rules for the tax rates are given by:

$$
\begin{aligned}
& \hat{\tau}_{t}^{w}=\rho_{w} \hat{\tau}_{t-1}^{w}+\left(1-\rho_{w}\right)\left(\eta_{w b} \hat{b}_{t-1}+\eta_{w h} \hat{l}_{t}\right)+\epsilon_{t, \tau^{w}} \\
& \hat{\tau}_{t}^{k}=\rho_{k} \hat{\tau}_{t-1}^{k}+\left(1-\rho_{k}\right)\left(\eta_{k b} \hat{b}_{t-1}+\eta_{k I} \hat{I}_{t}\right)+\epsilon_{t, \tau^{k}}
\end{aligned}
$$

Additionally, the estimation of the model closed with the new rules allows us to check for the policy invariance of the private sector estimates and to verify the empirical relevance of the feedback variables.

The model is estimated given the data, the calibration, and the prior distribution presented in the subsections 3.1 and 3.2. We employ the same prior distribution for the AR(1) coefficients and the coefficients on public debt as in section 3.2. The prior distribution for the coefficients $\eta_{w h}$ and $\eta_{k I}$ are chosen identical to the prior distribution of the feedback coefficients $\eta_{w y}$ and $\eta_{k y}$. For both coefficients we assume a prior which is normally distributed with mean 0 and standard deviation 0.5 .

The model is estimated by running two random walk Metropolis-Hastings chains, each with 1,000,000 parameter vector draws. The first 90\% are discarded. An overview of the posterior estimates of the policy parameter is given in Table 3. The posterior statistics for the remaining structural parameters are reported in Table C-9 in Appendix C. Prior and posterior distributions are illustrated in Figure C-6, Figure C-7, and Figure C-8. The plots show that the posterior distributions of the structural parameters are almost identical to those presented in Section 3.2. Consequently, all parameters except for $\sigma_{l}$ are identified and 

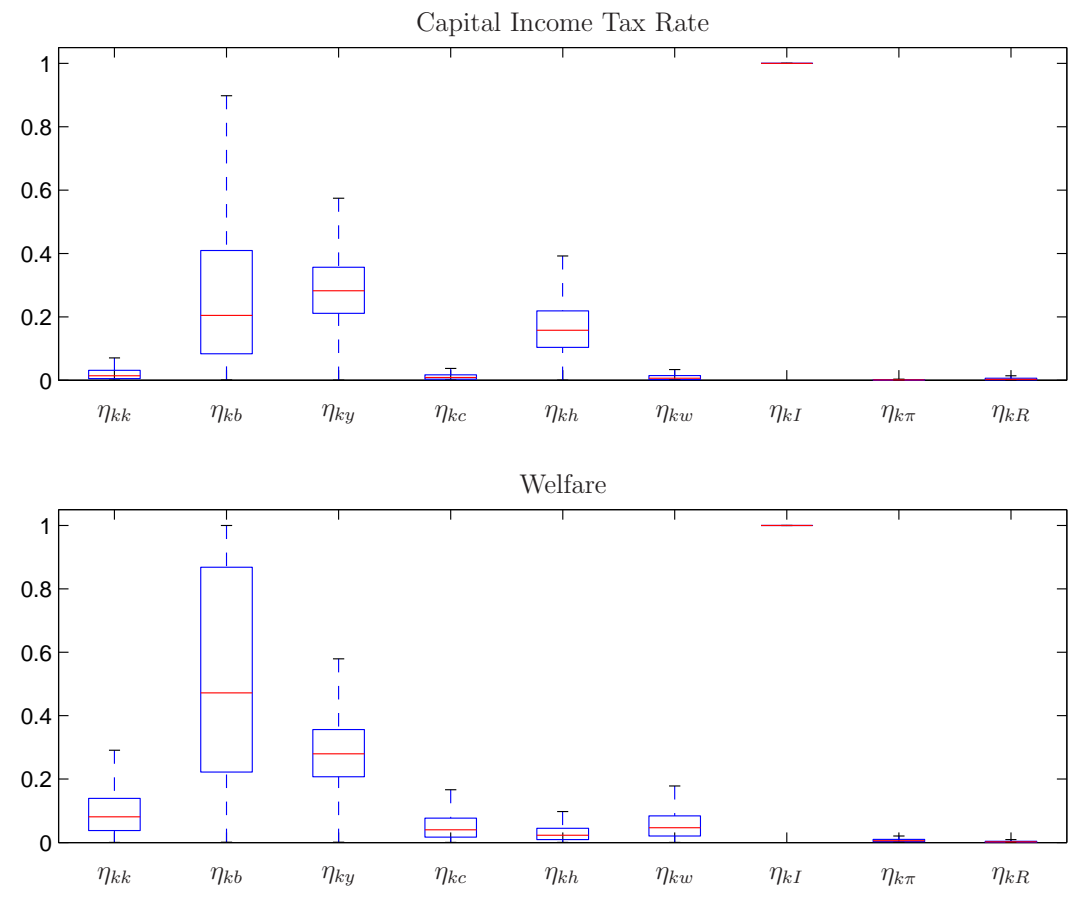

Figure 4: Relative elasticity of variables' variance w.r.t. feedback parameters of the capital income tax rule.

the posterior estimates of the structural parameters are policy invariant.

\begin{tabular}{lccccc}
\hline \hline Parameter & Symbol & Mode & Mean & $10 \%$ & $90 \%$ \\
\hline & & & & & \\
Labor tax AR coefficient & $\rho_{w}$ & 0.8195 & 0.8355 & 0.7485 & 0.9296 \\
Labor tax debt coefficient & $\eta_{w b}$ & 0.2346 & 0.3064 & 0.0883 & 0.5187 \\
Labor tax labor coefficient & $\eta_{w h}$ & 0.6710 & 0.5746 & -0.1392 & 1.3256 \\
Capital tax AR coefficient & $\rho_{k}$ & 0.8126 & 0.8234 & 0.7434 & 0.9043 \\
Capital tax debt coefficient & $\eta_{k b}$ & 0.2377 & 0.2693 & 0.0692 & 0.4486 \\
Capital tax investment coefficient & $\eta_{k I}$ & 0.3434 & 0.3533 & 0.0377 & 0.6779 \\
\hline \hline
\end{tabular}

Table 3: Posterior mode and posterior distribution of the new fiscal feedback rule.

With respect to our estimated policy rules, we find that all feedback parameters are identified and except for $\eta_{w h}$ different from zero. Both auto-regressive coefficients are estimated to be smaller: $\rho_{w}=0.82<0.86$ and $\rho_{k}=0.81<0.82$. The feedback coefficients on debt are also slightly smaller: $\eta_{w b}=0.23<0.29$ and $\eta_{k b}=0.24<0.26$. We estimate the feedback coefficient of the capital income tax rate on investment $\eta_{k I}=0.34$, and the feedback coefficient of labor income taxes with respect to hours worked $\eta_{w h}=0.67$.

In the following we want to compare the model closed with the rules (24) and (25) with the baseline model from Section 3.2. We use the Modified Harmonic Mean estimator by Geweke (1999) to calculate the marginal data density $\omega$ of each model $i$. The marginal data 

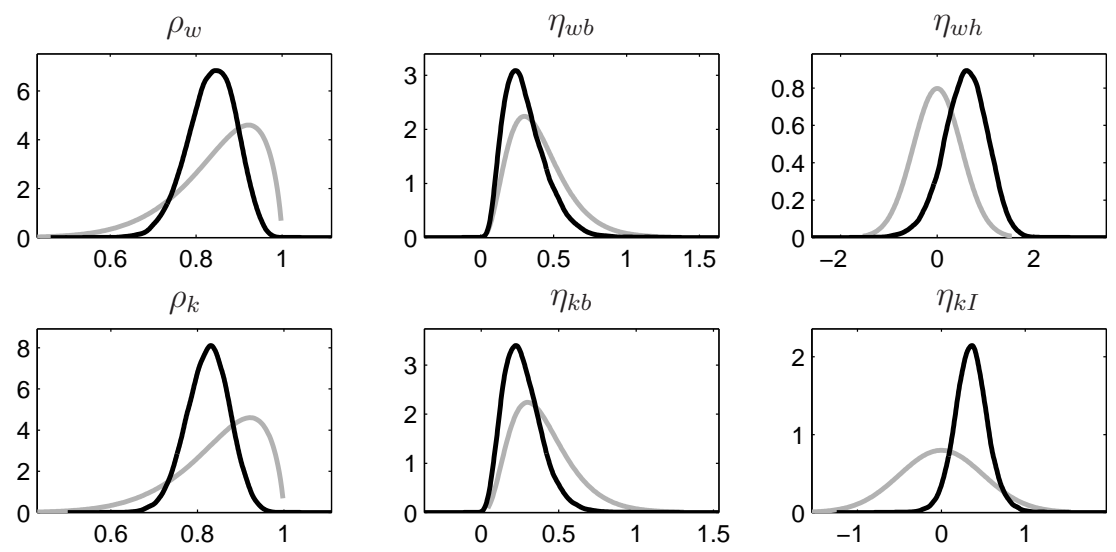

Figure 5: Prior (grey dashed) and posterior (black solid) distribution of policy feedback parameters.

density for model $i$ is:

$$
\omega\left(X \mid M_{i}\right)=\int_{\Theta_{i}} p\left(X \mid \theta_{i}\right) \pi_{i}\left(\theta_{i}\right) d \theta_{i},
$$

where $p\left(X \mid \theta_{i}\right)$ is the posterior, $\pi_{i}\left(\theta_{i}\right)$ the prior, and $\Theta_{i}$ the parameter space of model $i .{ }^{14}$ We denote the model closed with standard rules from section 3.2 as $M_{1}$ and the model closed with the feedback rules (25) and (24) as $M_{2}$. Given the marginal data densities the posterior probability on model $i$ is $\omega\left(X \mid M_{i}\right) / \sum_{j} \omega\left(X \mid M_{j}\right) ; j=1,2$. The difference in the marginal data density leads to posterior probabilities of 0.76 vs. 0.24 in favor of the model closed with the newly derived policy rules. ${ }^{15}$ Given that we have only changed two feedback variables, we think of this is as a strong empirical support for normative founded feedback coefficients.

\section{Conclusion}

In this paper we have determined the variables in a feedback rule for taxes on capital income and labor income that capture the automatic stabilizers within a DSGE model. To that end, we have employed an idea similar to the Taylor-rule in monetary economics: while the empirically observed Taylor-type rule itself is not optimal, its feedback variables are the correct choice of a welfare-maximizing policy maker. Consequently, we have first determined the feedback variables that influence the tax rates at the optimal allocation most. These are investment for taxes on capital income and hours worked for taxes on labor income. Afterwards, we have estimated the so determined policy feedback rules.

\footnotetext{
${ }^{14}$ As pointed out by Sims (2003) the choice of the prior distribution affects the marginal data density. In our model comparison we employ the same prior in the sense that we assume in each case the same normal distribution for a contemporaneous feedback variable and thus introduce an equivalent amount of uncertainty. For the sake of robustness we have checked our posterior probability using a trainings sample as suggested by Sims (2003).

${ }^{15}$ The relatively small difference in the log data density could be misleading. The numbers compared are the exponents of the logs.
} 
As a first result, we can identify both feedback coefficients in the data. The coefficient in front of investment is estimated significantly different from zero. This is in contrast to estimation of standard rules which include output as a feedback variable and have difficulties to identify the coefficient in front of output. Correspondingly, the posterior probabilities are strongly in favor of the rules determined in this paper. 


\section{A Data Description}

The frequency of all final data used is quarterly.

Real GDP: This series is BEA NIPA table 1.1.6 line 1.

Nominal GDP: This series is BEA NIPA table 1.1.5 line 1.

Implicit GDP Deflator: The implicit GDP deflator is calculated as the ratio of nominal GDP to real GDP.

Private Consumption: This series is defined as private consumption of non-durable goods (BEA NIPA table 1.1.5 line 5) and private consumption of services (BEA NIPA table 1.1.5 line 6$)$.

Private Investment: This series is gross private domestic investment ( $B E A$ NIPA table 1.1.5 line 7) plus private consumption of durable goods (BEA NIPA table 1.1.5 line 4).

Government Transfers: This series is defined as net current transfers, net capital transfers, and subsidies (BEA NIPA table 3.2 line 32). In addition, net current transfers are current transfer payments (BEA NIPA table 3.1 line 22) minus current transfer receipts (BEA NIPA table 3.2 line 15), net capital transfers are defined as the difference between capital transfer payments (BEA NIPA table 3.2 line 43) and capital transfer receipts (BEA NIPA table 3.2 line 39).

Nominal Interest Rate: The quarterly nominal interest rate is defined as the averages of daily figures of the fed funds fate obtained from the Board of Governors of the Federal Reserve System.

Inflation: The gross inflation rate is defined as the change in the implicit GDP deflator.

Population: This series is defined as the civilian noninstitutional population (CNP16OV), age 16 and over provided by the U.S. Department of Labor: Bureau of Labor Statistics: source: http://research.stlouisfed.org/fred2/series/CNP16OV?cid=104.

Tax Rates: Capital and labor tax rates are calculated following Jones (2002), where the labor tax rate is computed as:

$$
\tau^{w}=\frac{F I T+S I T}{W+P R I / 2+C I} \cdot \frac{(W+P R I / 2)}{E C+P R I / 2}+\frac{C S I}{E C+P R I / 2},
$$

where CSI denotes total contributions to social insurance (BEA NIPA table 3.1 line 7), EC denotes compensation of employees (BEA NIPA table 1.12 line 2), FIT denotes federal personal current taxes (BEA NIPA table 3.2 line 3), SIT denotes state and local personal current taxes (BEA NIPA table 3.3 line 3), PRI denotes proprietors' income ( $B E A$ NIPA table 1.12 line 9$), W$ denotes wage and salary accruals ( $B E A$ NIPA table 1.12 line 3), and CI is capital income. Capital income is defined as rental 
income (BEA NIPA table 1.12 line 12), corporate profits (BEA NIPA table 1.12 line 13), interest income (BEA NIPA table 1.12 line 18), and PRI/2. The average capital income tax rate is computed as:

$$
\tau^{k}=\frac{F I T+S I T}{W+P R I / 2+C I} \cdot \frac{C I}{C I+P T}+\frac{C T+P T}{C I+P T}
$$

where $C T$ denotes taxes on corporate income (BEA NIPA table 3.1 line 5) and PT denotes property taxes (BEA NIPA table 3.3 line 8).

Government Tax Revenues: Tax revenues, $x$, are defined as the sum of capital income taxes and taxes on labor. They are computed as:

$$
x=\tau^{w} \cdot(E C+P R I / 2)+\tau^{k} \cdot(C I+P T) .
$$

\section{B Equations of the model}

\section{B.1 First-order conditions households}

Since the first-order conditions for household $i$ are identical to the first-order conditions after aggregation, we report the aggregated first-order conditions for the sake of space.

$$
\begin{aligned}
\chi_{t} & =\left(c_{t}-h c_{t-1}\right)^{-\sigma_{c}}-\beta h\left(c_{t+1}-h c_{t}\right)^{-\sigma_{c}} \\
\frac{1}{R_{t}^{b}} & =\beta \frac{\chi_{t+1} \varepsilon_{q, t}}{\chi_{t} \pi_{t+1}^{p}} \\
q_{t} & =\beta E_{t}\left[\frac{\chi_{t+1}}{\chi_{t}}\left(\psi^{\prime}\left(u_{t+1}\right) u_{t+1}-\psi\left(u_{t+1}\right)+q_{t+1}(1-\delta)\right)\right] \\
\phi_{t}^{\prime} & =r_{t}^{k}\left(1-\tau_{t}^{k}\right) \\
q_{t} & =\frac{1-\beta E_{t}\left[\frac{\chi_{t+1}}{\chi_{t}} q_{t+1} s_{t+1}^{\prime} \varepsilon_{i, t+1}\left(\frac{I_{t+1}}{I_{t}}\right)^{2}\right]}{1-s_{t}-s_{t}^{\prime} \frac{\varepsilon_{i, t} I_{t}}{I_{t-1}}}
\end{aligned}
$$

In the foregoing equations, $\chi_{t}$ denotes the marginal utility of consumption and $q_{t}$ the marginal utility of capital relative to the marginal utility of consumption.

Real wage inflation $\pi^{w}$ :

$$
\pi_{t}^{w}=\frac{w_{t}}{w_{t-1}} \pi_{t}
$$

The first-order condition to the maximization problem (5) in recursive form as:

$$
K_{t}^{w}=\left(l_{t}^{d}\right)^{1+\sigma_{l}}+\beta \gamma_{w}\left(\frac{\bar{\pi}}{\pi_{t+1}^{w}}\right)^{-\theta_{w}\left(1+\sigma_{l}\right)} K_{t+1}^{w}
$$




$$
\begin{gathered}
F_{t}^{w}=\frac{\left(\theta_{w}-1\right)}{\theta_{w}}\left(1-\tau_{t}^{w}\right) l_{t}^{d} \chi_{t}+\beta \gamma_{w}\left(\frac{\pi_{t+1}}{\pi_{t+1}^{w}}\right)^{-\theta_{w}}\left(\frac{\bar{\pi}}{\pi_{t+1}}\right)^{1-\theta_{w}} F_{t+1}^{w} \\
\frac{K_{t}^{w}}{F_{t}^{w}}=\frac{1}{\psi_{l}}\left(w_{t}^{*}\right)^{1+\theta_{w} \sigma_{l}} w_{t}
\end{gathered}
$$

The law of motion for $w_{t}^{*}=\frac{W_{t}^{\star}}{W_{t}}$ is given by:

$$
1=\gamma_{w}\left(\frac{\bar{\pi}}{\pi_{t}^{w}}\right)^{1-\theta_{w}}+\left(1-\gamma_{w}\right)\left(w_{t}^{*}\right)^{1-\theta_{w}}
$$

\section{B.2 First-order conditions intermediate good firm}

Marginal costs are denoted by $z$. The first-order conditions of (8) are given by:

$$
\begin{gathered}
z_{t}(1-\alpha)\left(u_{t} k_{t-1}\right)^{\alpha}\left(l_{t}^{d} \varepsilon_{z, t}\right)^{-\alpha}=w_{t} \\
z_{t} \alpha\left(u_{t} k_{t-1}\right)^{\alpha-1}\left(l_{t}^{d} \varepsilon_{z, t}\right)^{1-\alpha}=r_{t}^{k}
\end{gathered}
$$

The profits $d_{t}$ of the intermediate firm are then defined as:

$$
d_{t}=y_{t}-r_{t}^{k} u_{t} k_{t-1}-w_{t} l_{t}^{d}
$$

Define $p_{t}^{*}=\frac{P_{t}^{\star}}{P_{t}}$. Using the demand for firm $j$ and the aggregate price index, we rewrite the first-order condition to the maximization problem (9) and the law of motion for $p_{t}^{*}$ as:

$$
\begin{gathered}
F_{t}^{p}=y_{t}^{d} \chi_{t}+\gamma_{p} \beta\left(\frac{\bar{\pi}}{\pi_{t+1}}\right)^{1-\theta_{p}} F_{t+1}^{p} \\
K_{t}^{p}=\frac{\theta_{p}}{\theta_{p}-1} y_{t}^{d} \chi_{t} z_{t}+\gamma_{p} \beta\left(\frac{\bar{\pi}}{\pi_{t+1}}\right)^{-\theta_{p}} K_{t+1}^{p} \\
\frac{K_{t}^{p}}{F_{t}^{p}}=p_{t}^{*} \\
1=\gamma_{p}\left(\frac{\bar{\pi}}{\pi_{t}}\right)^{1-\theta_{p}}+\left(1-\gamma_{p}\right)\left(p_{t}^{*}\right)^{1-\theta_{p}}
\end{gathered}
$$

\section{B.3 Functional forms and stochastic processes}

Cost of capacity utilization $\phi(\cdot)$ :

$$
\phi_{t}(u)=\frac{\left(1-\bar{\tau}_{k}\right) \bar{r}^{k}}{\sigma_{u}}\left(\exp \left(\sigma_{u}\left(u_{t}-1\right)\right)-1\right)
$$

Investment adjustment cost $s(\cdot)$

$$
s_{t}\left(\frac{\varepsilon_{i, t} I_{t}}{I_{t-1}}\right)=\frac{\nu}{2}\left(\frac{\varepsilon_{i, t} I_{t}}{I_{t-1}}-1\right)^{2},
$$


Risk premium shock $\varepsilon_{q, t}$ :

$$
\log \varepsilon_{q, t}=\rho_{q} \log \varepsilon_{q, t-1}+\epsilon_{t}^{q}, \quad \epsilon^{q} i . i . d .
$$

Investment-specific efficiency shock to the adjustment $\operatorname{costs} \varepsilon_{i}$ :

$$
\log \varepsilon_{i, t}=\rho_{i} \log \varepsilon_{i, t-1}+\epsilon_{t}^{i}, \quad \epsilon^{i} i . i . d .
$$

Labor-augmenting productivity shock $\varepsilon_{z}$

$$
\log \varepsilon_{z, t}=\rho_{z} \log \varepsilon_{z, t-1}+\epsilon_{t}^{z}, \quad \epsilon^{z} i . i . d .
$$

Government consumption expenditures $c^{g}$

$$
\log c_{t}^{g}=\rho_{c g} \log c_{t-1}^{g}+\left(1-\rho_{c g}\right) \log \bar{c}^{g}+\epsilon_{t}^{c g} \quad \epsilon^{c g} i . i . d
$$

Lump-sum taxes $\tau^{L}$ :

$$
\log \tau_{t}^{L}=\rho_{L} \log \tau_{t-1}^{L}+\left(1-\rho_{L}\right) \log \bar{\tau}^{L}+\epsilon_{t}^{L} \quad \epsilon^{L} \text { i.i.d. }
$$

\section{B.4 Aggregation}

We use the variable $p_{t}^{+}$to capture the resource costs induced by inefficient price dispersion:

$$
p_{t}^{+}=\left(1-\gamma_{p}\right)\left(p_{t}^{*}\right)^{-\theta_{p}}+\gamma_{p}\left(\frac{\bar{\pi}}{\pi_{t}}\right)^{-\theta_{p}} p_{t-1}^{+}
$$

$w_{t}^{+}$captures the loss in output caused by wage dispersion into account, we use the variable:

$$
w_{t}^{+}=\left(1-\gamma_{w}\right)\left(w_{t}^{*}\right)^{-\theta_{w}}+\gamma_{w}\left(\frac{\bar{\pi}}{\pi_{t}^{w}}\right)^{-\theta_{w}} w_{t-1}^{+}
$$

The equilibrium condition of the labor market then becomes:

$$
l_{t}=w_{t}^{+} l_{t}^{d}
$$

The dispersion of wages causes a dispersion in utility across households. This dispersion is measured by the variable $\tilde{w}_{t}^{+}$:

$$
\tilde{w}_{t}^{+}=\left(1-\gamma_{w}\right)\left(w_{t}^{*}\right)^{-\theta_{w}\left(1+\sigma_{l}\right)}+\gamma_{w}\left(\frac{\bar{\pi}}{\pi_{t}^{w}}\right)^{-\theta_{w}\left(1+\sigma_{l}\right)} \tilde{w}_{t-1}^{+}
$$

The resource constraint of the economy is given by

$$
\frac{\left(\left(u_{t} k_{t-1}\right)^{\alpha}\left(l_{t}^{d} \varepsilon_{z, t}\right)^{1-\alpha}-\Omega\right)}{p_{t}^{+}}=c_{t}+I_{t}+c_{t}^{g}+\phi_{t}\left(u_{t}\right) k_{t-1}
$$


The aggregated utility across households is given by:

$$
U_{t}=\frac{\left(c_{t}-h c_{t-1}\right)^{1-\sigma_{c}}}{1-\sigma_{c}}-\frac{\tilde{w}_{t}^{+}\left(\frac{l_{t}}{w_{t}^{+}}\right)^{1+\sigma_{l}}}{1+\sigma_{l}}
$$

\section{B.5 Optimal policy setup}

Let $N$ be the number of endogenous variables. ${ }^{16}$ The optimal policy problem is defined as maximizing the lifetime expected utility

$$
E_{0} \sum_{t=0}^{\infty} \beta^{t} U\left(c_{t}-h c_{t-1}, l_{t}\right)
$$

where aggregate utility is defined by Equation (B-30), subject to the following $(N-2)$ equations: (3), (12), (B-1)-(B-19), (B-25)-(B-30).

The first-order conditions of the maximization problem yield $2 N-2$ equations for the $N$ endogenous variables and $N-2$ Lagrangian multipliers associated with the private sector equilibrium constraints.

The optimal equilibrium is then defined as a set of stationary variables $F_{t}^{w}, F_{t}^{p}, K_{t}^{w}$, $K_{t}^{p}, p_{t}^{*}, w_{t}^{*}, d_{t}, p_{t}^{+}, w_{t}^{+}, \pi_{t}^{w}, \pi_{t}, w_{t}, y_{t}, l_{t}, k_{t}, z_{t}, \varepsilon_{i, t}, \varepsilon_{z, t}, \varepsilon_{q, t}, s_{t}, \phi_{t}, \chi_{t}, I_{t}, c_{t}, u_{t}, r_{t}^{k}, l_{t}^{d}$, $b_{t}, t_{t}, R_{t}, \tau_{t}^{L}, \tau_{t}^{w}, \tau_{t}^{k}, c_{t}^{g}, \tilde{w}_{t}^{+}$, and $N-2$ Lagrangian multipliers satisfying the first-order conditions of the optimal policy problem, as well as the laws of motion for the autoregressive shock processes (B-20), (B-22), (B-21), (B-23), (B-24), given exogenous stochastic processes $\left\{\epsilon_{t}^{i}, \epsilon_{t}^{q}, \epsilon_{t}^{z}, \epsilon_{t}^{c g}, \epsilon_{t}^{L}, \epsilon_{t}^{m}\right\}_{t=0}^{\infty}$, values of the $N$ endogenous variables dated $t<0$, and values of the $(N-2)$ Lagrangian multipliers dated $t<0$.

\footnotetext{
${ }^{16}$ In our benchmark model the number of endogenous variables is $N=30$.
} 


\section{Tables and Figures}

\begin{tabular}{lcc}
\hline \hline & & \\
Description & Symbol & Value \\
\hline Discount factor & $\beta$ & 0.993 \\
Capital share & $\alpha$ & 0.4 \\
Depreciation rate & $\delta$ & 0.025 \\
Price markup & $\theta_{p} /\left(\theta_{p}-1\right)$ & 1.2 \\
Wage markup & $\theta_{w} /\left(\theta_{w}-1\right)$ & 1.1 \\
Annualized nominal interest rate & $\bar{R}$ & 1.0543 \\
Ratio of government consumption to output & $\bar{c}^{g} / \bar{y}$ & 0.19 \\
Ratio of government transfers to output & $\bar{\tau}^{l} / \bar{y}$ & -0.08 \\
Steady-state capital tax rate & $\bar{\tau}_{k}$ & 0.3572 \\
Steady-state labor tax rate & $\bar{\tau}_{w}$ & 0.2343 \\
\hline \hline
\end{tabular}

Table C-4: Parameter calibration. 


\begin{tabular}{|c|c|c|c|c|c|}
\hline Parameter & Symbol & Domain & Density & $\operatorname{Para}(1)$ & $\operatorname{Para}(2)$ \\
\hline Inv. intertemp. subst. elasticity & $\sigma_{c}$ & $\mathbb{R}^{+}$ & Gamma & 1.75 & 0.5 \\
\hline Inverse Frisch elasticity & $\sigma_{l}$ & $\mathbb{R}^{+}$ & Gamma & 2.0 & 0.5 \\
\hline Habit persistence & $h$ & {$[0,1)$} & Beta & 0.5 & 0.15 \\
\hline Calvo parameter prices & $\gamma_{p}$ & {$[0,1)$} & Beta & 0.5 & 0.15 \\
\hline Calvo parameter wages & $\gamma_{w}$ & {$[0,1)$} & Beta & 0.5 & 0.15 \\
\hline Investment adjustment cost & $\nu$ & $\mathbb{R}^{+}$ & Gamma & 4 & 1.25 \\
\hline Capital utilization cost & $\sigma_{u}$ & $\mathbb{R}^{+}$ & Gamma & 2 & 0.5 \\
\hline Interest rate $\mathrm{AR}$ coefficient & $\rho_{R}$ & {$[0,1)$} & Beta & 0.8 & 0.1 \\
\hline Interest rate inflation coefficient & $\rho_{\pi}$ & $\mathbb{R}^{+}$ & Gamma & 1.7 & 0.1 \\
\hline Interest rate output coefficient & $\rho_{y}$ & $\mathbb{R}$ & Gamma & 0.125 & 0.05 \\
\hline Labor tax AR coefficient & $\rho_{w}$ & {$[0,1)$} & Beta & 0.85 & 0.1 \\
\hline Labor tax debt coefficient & $\eta_{w b}$ & $\mathbb{R}^{+}$ & Gamma & 0.4 & 0.2 \\
\hline Labor tax output coefficient & $\eta_{w y}$ & $\mathbb{R}$ & Normal & 0 & 0.5 \\
\hline Capital tax AR coefficient & $\rho_{k}$ & {$[0,1)$} & Beta & 0.85 & 0.1 \\
\hline Capital tax debt coefficient & $\eta_{k b}$ & $\mathbb{R}^{+}$ & Gamma & 0.4 & 0.2 \\
\hline Capital tax output coefficient & $\eta_{k y}$ & $\mathbb{R}$ & Normal & 0 & 0.5 \\
\hline Lump-sum tax AR coefficient & $\rho_{\tau^{l}}$ & {$[0,1)$} & Beta & 0.85 & 0.1 \\
\hline Adjustment costs AR coefficient & $\rho_{i}$ & {$[0,1)$} & Beta & 0.85 & 0.1 \\
\hline Technology AR coefficient & $\rho_{z}$ & {$[0,1)$} & Beta & 0.85 & 0.1 \\
\hline Public consumption AR coefficient & $\rho_{c g}$ & {$[0,1)$} & Beta & 0.85 & 0.1 \\
\hline S.d. adjustment costs shock & $\epsilon_{i}$ & $\mathbb{R}^{+}$ & InvGam & 0.01 & 4.0 \\
\hline S.d. technology shock & $\epsilon_{z}$ & $\mathbb{R}^{+}$ & InvGam & 0.01 & 4.0 \\
\hline S.d. finance premium shock & $\epsilon_{q}$ & $\mathbb{R}^{+}$ & InvGam & 0.01 & 4.0 \\
\hline S.d. monetary policy shock & $\epsilon_{m}$ & $\mathbb{R}^{+}$ & InvGam & 0.01 & 4.0 \\
\hline S.d. wage tax shock & $\epsilon_{\tau^{w}}$ & $\mathbb{R}^{+}$ & InvGam & 0.01 & 4.0 \\
\hline S.d. capital tax shock & $\epsilon_{\tau^{k}}$ & $\mathbb{R}^{+}$ & InvGam & 0.01 & 4.0 \\
\hline S.d. lump-sum tax shock & $\epsilon_{\tau^{l}}$ & $\mathbb{R}^{+}$ & InvGam & 0.01 & 4.0 \\
\hline S.d. public consumption shock & $\epsilon_{c g}$ & $\mathbb{R}^{+}$ & InvGam & 0.01 & 4.0 \\
\hline S.d. measurement error taxes & $\epsilon_{\operatorname{tax}}$ & $\mathbb{R}^{+}$ & InvGam & 0.01 & 4.0 \\
\hline
\end{tabular}

Table C-5: Prior distribution of model parameters. Para(1) and Para(2) correspond to means and standard deviations for the Beta, Gamma, Inverted Gamma, and Normal distribution. 


\begin{tabular}{|c|c|c|c|c|c|}
\hline Parameter & Symbol & Mode & Mean & $10 \%$ & $90 \%$ \\
\hline Inv. intertemp. subst. elasticity & $\sigma_{c}$ & 1.6444 & 1.7692 & 1.1765 & 2.3773 \\
\hline Inverse Frisch elasticity & $\sigma_{l}$ & 1.8284 & 1.9383 & 1.1532 & 2.7120 \\
\hline Habit persistence & $h$ & 0.4519 & 0.4520 & 0.3274 & 0.5704 \\
\hline Price stickiness & $\gamma_{p}$ & 0.6495 & 0.6547 & 0.5877 & 0.7249 \\
\hline Wage stickiness & $\gamma_{w}$ & 0.6511 & 0.6392 & 0.5359 & 0.7472 \\
\hline Investment adjustment cost & $\nu$ & 3.8930 & 4.3250 & 2.4786 & 6.0662 \\
\hline Capital utilization cost & $\sigma_{u}$ & 3.0383 & 3.1623 & 2.3207 & 3.9756 \\
\hline Interest rate $\mathrm{AR}$ coefficient & $\rho_{R}$ & 0.7983 & 0.7991 & 0.7597 & 0.8395 \\
\hline Inflation coefficient & $\rho_{\pi}$ & 1.7835 & 1.7915 & 1.6286 & 1.9476 \\
\hline Output coefficient & $\rho_{y}$ & 0.1194 & 0.1230 & 0.0691 & 0.1718 \\
\hline Labor tax AR coefficient & $\rho_{w}$ & 0.8577 & 0.8586 & 0.7842 & 0.9405 \\
\hline Labor tax debt coefficient & $\eta_{w b}$ & 0.2887 & 0.3406 & 0.1003 & 0.5574 \\
\hline Labor tax output coefficient & $\eta_{w y}$ & 0.1106 & 0.0883 & -0.6154 & 0.7909 \\
\hline Capital tax AR coefficient & $\rho_{k}$ & 0.8162 & 0.8219 & 0.7410 & 0.9045 \\
\hline Capital tax debt coefficient & $\eta_{k b}$ & 0.2565 & 0.2915 & 0.0819 & 0.4891 \\
\hline Capital tax output coefficient & $\eta_{k y}$ & 0.5257 & 0.5035 & -0.1822 & 1.1866 \\
\hline Lump-sum tax AR coefficient & $\rho_{\tau^{l}}$ & 0.7617 & 0.7598 & 0.6572 & 0.8605 \\
\hline Adjustment costs AR coefficient & $\rho_{i}$ & 0.4923 & 0.5032 & 0.3742 & 0.6333 \\
\hline Technology AR coefficient & $\rho_{z}$ & 0.9214 & 0.9132 & 0.8622 & 0.9680 \\
\hline Risk premium AR coefficient & $\rho_{q}$ & 0.8335 & 0.8169 & 0.7370 & 0.8962 \\
\hline Public consumption AR coefficient & $\rho_{c g}$ & 0.8377 & 0.8358 & 0.7515 & 0.9229 \\
\hline S.d. adjustment costs shock & $\epsilon_{i}$ & 0.0292 & 0.0304 & 0.0251 & 0.0356 \\
\hline S.d. technology shock & $\epsilon_{z}$ & 0.0078 & 0.0084 & 0.0063 & 0.0104 \\
\hline S.d. risk premium shock & $\epsilon_{q}$ & 0.0039 & 0.0045 & 0.0026 & 0.0065 \\
\hline S.d. monetary policy shock & $\epsilon_{m}$ & 0.0015 & 0.0015 & 0.0013 & 0.0017 \\
\hline S.d. labor tax shock & $\epsilon_{\tau^{w}}$ & 0.0215 & 0.0219 & 0.0193 & 0.0244 \\
\hline S.d. capital tax shock & $\epsilon_{\tau^{k}}$ & 0.0236 & 0.0240 & 0.0212 & 0.0267 \\
\hline S.d. lump-sum tax shock & $\epsilon_{\tau^{l}}$ & 0.0235 & 0.0239 & 0.0211 & 0.0264 \\
\hline S.d. public consumption shock & $\epsilon_{c g}$ & 0.0141 & 0.0143 & 0.0126 & 0.0159 \\
\hline S.d. measurement error taxes & $\epsilon_{\operatorname{tax}}$ & 0.0102 & 0.0104 & 0.0092 & 0.0116 \\
\hline Log data density & \multicolumn{5}{|c|}{3133.681} \\
\hline
\end{tabular}

Table C-6: Posterior mode and posterior distribution of the benchmark model's parameters. 

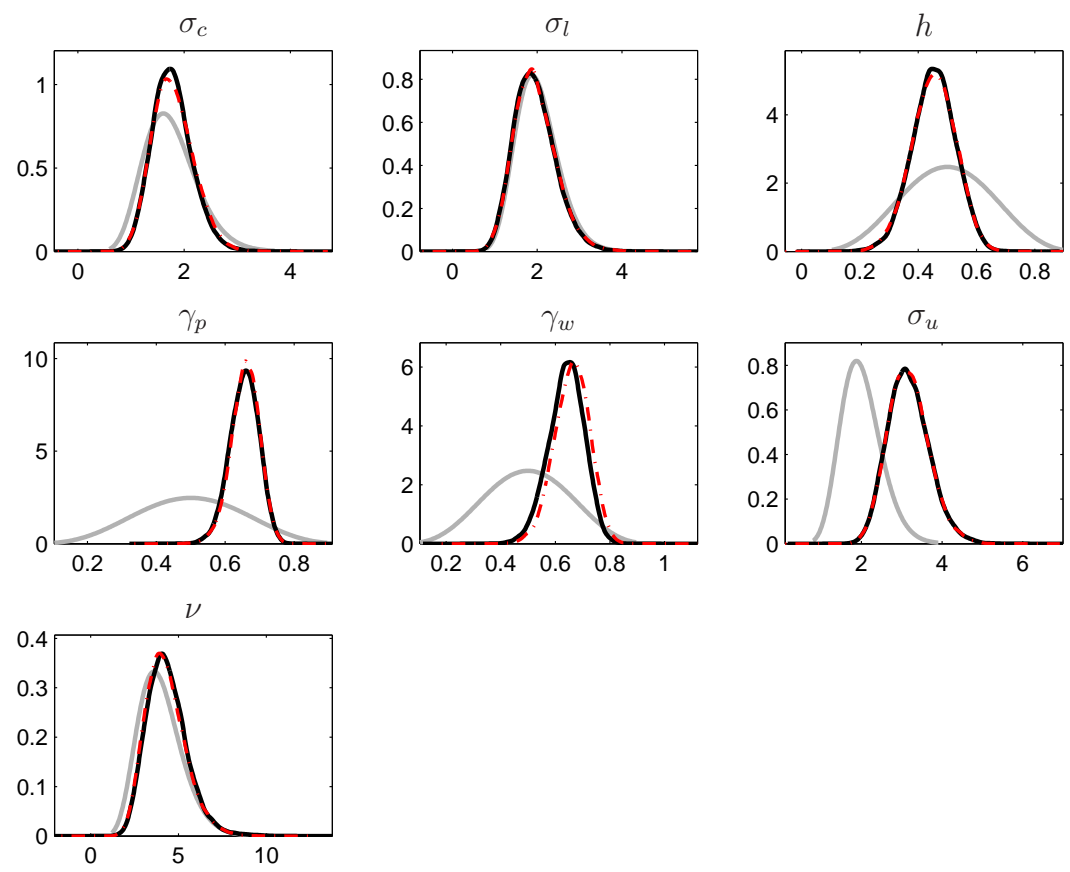

Prior $—$ Posterior Baseline - - - Posterior Extended

Figure C-6: Prior vs. Posterior plots (1).
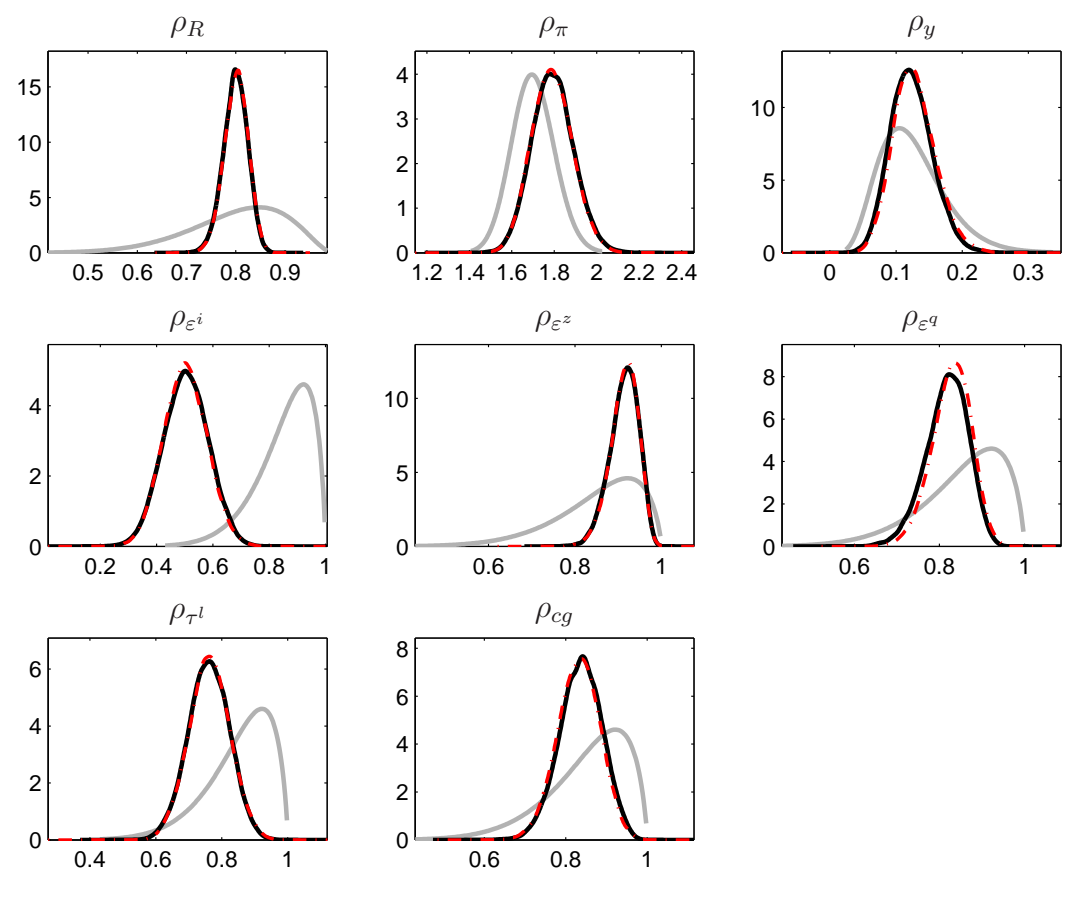

Prior — Posterior Baseline - - - Posterior Extended

Figure C-7: Prior vs. Posterior plots (2). 
s.d. $\epsilon_{i}$

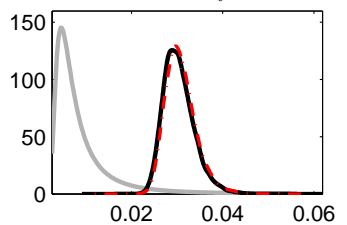

s.d. $\epsilon_{m}$

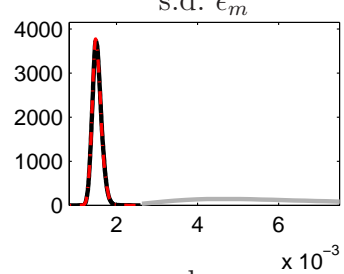

s.d. $\epsilon_{c g}$

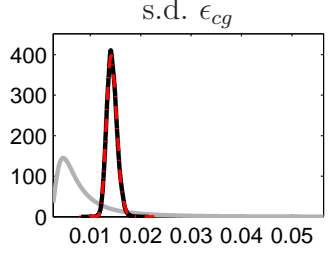

Prior s.d. $\epsilon_{z}$

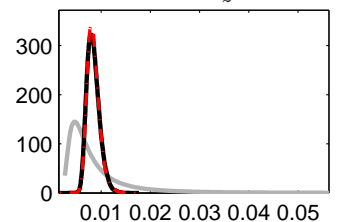

s.d. $\epsilon_{\tau^{w}}$

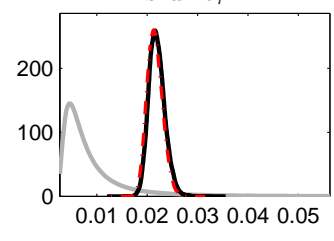

s.d. $\epsilon_{\tau^{l}}$

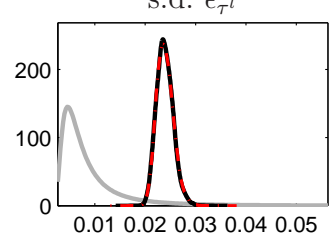

s.d. $\epsilon_{q}$

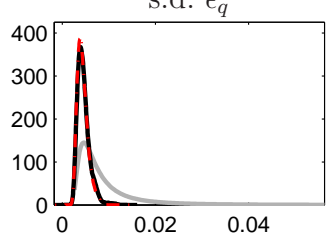

s.d. $\epsilon_{\tau^{k}}$

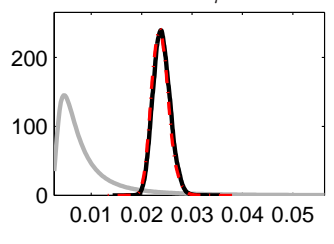

s.d. $\epsilon_{\operatorname{tax}}$

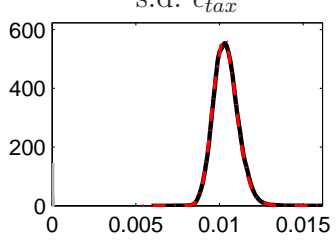

Figure C-8: Prior vs. Posterior plots (3). 


\begin{tabular}{lcccc}
\hline \hline \multirow{4}{*}{ Feedback Parameter } & Symbol & \multicolumn{3}{c}{ Percentile } \\
& \multicolumn{5}{c}{$50 \%$} & $25 \%$ & $75 \%$ \\
\hline \multicolumn{5}{c}{ TAX RATE ON LABOR INCOME } \\
\hline \multicolumn{5}{c}{} \\
Capital & $\eta_{w k}$ & 0.3043 & 0.1349 & 0.6144 \\
Debt & $\eta_{w b}$ & 0.2862 & 0.1887 & 0.3997 \\
Output & $\eta_{w y}$ & 0.3346 & 0.1290 & 0.6545 \\
Consumption & $\eta_{w c}$ & 0.0710 & 0.0288 & 0.1535 \\
Hours worked & $\eta_{w h}$ & 2.6759 & 2.1992 & 3.1114 \\
Wage rate & $\eta_{w w}$ & 0.1675 & 0.0519 & 0.4079 \\
Investment & $\eta_{w I}$ & 0.4187 & 0.1979 & 0.7160 \\
Inflation & $\eta_{w \pi}$ & 0.0317 & 0.0116 & 0.0703 \\
Nominal interest rate & $\eta_{w R}$ & 0.0575 & 0.0240 & 0.1092 \\
\hline
\end{tabular}

Tax Rate on Capital Income

\begin{tabular}{lcccc}
\hline Capital & $\eta_{k k}$ & 0.0155 & 0.0055 & 0.0345 \\
Debt & $\eta_{k b}$ & 0.2312 & 0.1062 & 0.4001 \\
Output & $\eta_{k y}$ & 0.3193 & 0.2293 & 0.4115 \\
Consumption & $\eta_{k c}$ & 0.0098 & 0.0038 & 0.0201 \\
Hours worked & $\eta_{k h}$ & 0.1778 & 0.1144 & 0.2459 \\
Wage rate & $\eta_{k w}$ & 0.0068 & 0.0022 & 0.0166 \\
Investment & $\eta_{k I}$ & 1.1474 & 0.9480 & 1.3207 \\
Inflation & $\eta_{k \pi}$ & 0.0007 & 0.0003 & 0.0016 \\
Nominal interest rate & $\eta_{k R}$ & 0.0033 & 0.0012 & 0.0071 \\
\hline \hline
\end{tabular}

Table C-7: Elasticity of labor income tax rate's variance w.r.t. feedback parameters of the tax rules. 


\begin{tabular}{|c|c|c|c|c|}
\hline \multirow[t]{2}{*}{ Feedback Parameter } & \multirow[t]{2}{*}{ Symbol } & \multicolumn{3}{|c|}{ Percentile } \\
\hline & & $50 \%$ & $25 \%$ & $75 \%$ \\
\hline \multicolumn{5}{|c|}{ WELFARE } \\
\hline Capital & $\eta_{w k}$ & 0.2605 & 0.1319 & 0.4418 \\
\hline Debt & $\eta_{w b}$ & 0.0333 & 0.0135 & 0.0756 \\
\hline Output & $\eta_{w y}$ & 0.0494 & 0.0162 & 0.1167 \\
\hline Consumption & $\eta_{w c}$ & 0.0266 & 0.0090 & 0.0659 \\
\hline Hours worked & $\eta_{w h}$ & 0.2976 & 0.2193 & 0.3926 \\
\hline Wage rate & $\eta_{w w}$ & 0.0335 & 0.0115 & 0.0790 \\
\hline Investment & $\eta_{w I}$ & 0.0820 & 0.0332 & 0.1625 \\
\hline Inflation & $\eta_{w \pi}$ & 0.0055 & 0.0018 & 0.0138 \\
\hline Nominal interest rate & $\eta_{w R}$ & 0.0048 & 0.0016 & 0.0129 \\
\hline Capital & $\eta_{k k}$ & 0.0482 & 0.0228 & 0.0817 \\
\hline Debt & $\eta_{k b}$ & 0.2646 & 0.1240 & 0.4783 \\
\hline Output & $\eta_{k y}$ & 0.1679 & 0.1277 & 0.2085 \\
\hline Consumption & $\eta_{k c}$ & 0.0235 & 0.0100 & 0.0452 \\
\hline Hours worked & $\eta_{k h}$ & 0.0135 & 0.0055 & 0.0267 \\
\hline Wage rate & $\eta_{k w}$ & 0.0273 & 0.0124 & 0.0495 \\
\hline Investment & $\eta_{k I}$ & 0.5591 & 0.5026 & 0.6187 \\
\hline Inflation & $\eta_{k \pi}$ & 0.0032 & 0.0015 & 0.0059 \\
\hline Nominal interest rate & $\eta_{k R}$ & 0.0011 & 0.0004 & 0.0026 \\
\hline
\end{tabular}

Table C-8: Elasticity of welfare's variance w.r.t. feedback parameters of the tax rules. 


\begin{tabular}{|c|c|c|c|c|c|}
\hline Parameter & Symbol & Mode & Mean & $10 \%$ & $90 \%$ \\
\hline Inv. intertemp. subst. elasticity & $\sigma_{c}$ & 1.6411 & 1.7852 & 1.1695 & 2.4209 \\
\hline Inverse Frisch elasticity & $\sigma_{l}$ & 1.8538 & 1.9463 & 1.1625 & 2.7435 \\
\hline Habit persistence & $h$ & 0.4588 & 0.4517 & 0.3319 & 0.5785 \\
\hline Price stickiness & $\gamma_{p}$ & 0.6526 & 0.6572 & 0.5924 & 0.7261 \\
\hline Wage stickiness & $\gamma_{w}$ & 0.6778 & 0.6596 & 0.5585 & 0.7666 \\
\hline Investment adjustment cost & $\nu$ & 3.8854 & 4.2443 & 2.4205 & 5.9747 \\
\hline Capital utilization cost & $\sigma_{u}$ & 3.0301 & 3.1582 & 2.3275 & 3.9674 \\
\hline Interest rate $\mathrm{AR}$ coefficient & $\rho_{R}$ & 0.8007 & 0.8002 & 0.7593 & 0.8396 \\
\hline Inflation coefficient & $\rho_{\pi}$ & 1.7741 & 1.7882 & 1.6323 & 1.9437 \\
\hline Output coefficient & $\rho_{y}$ & 0.1237 & 0.1274 & 0.0753 & 0.1795 \\
\hline Labor tax AR coefficient & $\rho_{w}$ & 0.8195 & 0.8355 & 0.7485 & 0.9296 \\
\hline Labor tax debt coefficient & $\eta_{w b}$ & 0.2346 & 0.3064 & 0.0883 & 0.5187 \\
\hline Labor tax labor coefficient & $\eta_{w h}$ & 0.6710 & 0.5746 & -0.1392 & 1.3256 \\
\hline Capital tax AR coefficient & $\rho_{k}$ & 0.8126 & 0.8234 & 0.7434 & 0.9043 \\
\hline Capital tax debt coefficient & $\eta_{k b}$ & 0.2377 & 0.2693 & 0.0692 & 0.4486 \\
\hline Capital tax investment coefficient & $\eta_{k I}$ & 0.3434 & 0.3533 & 0.0377 & 0.6779 \\
\hline Lump-sum tax AR coefficient & $\rho_{\tau^{l}}$ & 0.7620 & 0.7613 & 0.6595 & 0.8630 \\
\hline Adjustment costs AR coefficient & $\rho_{i}$ & 0.4952 & 0.5011 & 0.3723 & 0.6230 \\
\hline Technology AR coefficient & $\rho_{z}$ & 0.9216 & 0.9132 & 0.8628 & 0.9668 \\
\hline Risk premium AR coefficient & $\rho_{q}$ & 0.8439 & 0.8275 & 0.7550 & 0.9041 \\
\hline Public consumption AR coefficient & $\rho_{c g}$ & 0.8335 & 0.8307 & 0.7445 & 0.9140 \\
\hline S.d. adjustment costs shock & $\epsilon_{i}$ & 0.0297 & 0.0308 & 0.0253 & 0.0358 \\
\hline S.d. technology shock & $\epsilon_{z}$ & 0.0079 & 0.0084 & 0.0064 & 0.0104 \\
\hline S.d. risk premium shock & $\epsilon_{q}$ & 0.0037 & 0.0043 & 0.0025 & 0.0060 \\
\hline S.d. monetary policy shock & $\epsilon_{m}$ & 0.0015 & 0.0015 & 0.0013 & 0.0017 \\
\hline S.d. labor tax shock & $\epsilon_{\tau} w$ & 0.0211 & 0.0215 & 0.0190 & 0.0241 \\
\hline S.d. capital tax shock & $\epsilon_{\tau^{k}}$ & 0.0233 & 0.0237 & 0.0209 & 0.0263 \\
\hline S.d. lump-sum tax shock & $\epsilon_{\tau}^{l}$ & 0.0235 & 0.0239 & 0.0212 & 0.0265 \\
\hline S.d. public consumption shock & $\epsilon_{c g}$ & 0.0140 & 0.0143 & 0.0126 & 0.0159 \\
\hline S.d. measurement error taxes & $\epsilon_{\text {tax }}$ & 0.0102 & 0.0104 & 0.0092 & 0.0115 \\
\hline Log data density & \multicolumn{5}{|c|}{3134.816} \\
\hline
\end{tabular}

Table C-9: Posterior mode and posterior distribution of the extended model's parameters. 


\section{References}

Altig, D., L. J. Christiano, M. Eichenbaum, And J. Lindé (2010): "Firm-specific capital, nominal rigidities and the business cycle," Review of Economic Dynamics, In Press, Corrected Proof.

Auerbach, A. (2002): "Is There a Role for Discretionary Fiscal Policy?" NBER Working Papers 9306, National Bureau of Economic Research, Inc.

Benigno, P. And M. Woodford (2006a): "Linear-Quadratic Approximation of Optimal Policy Problems," NBER Working Papers 12672, National Bureau of Economic Research, Inc.

(2006b): "Optimal Taxation in an RBC Model: A Linear-Quadratic Approach," Journal of Economic Dynamics and Control, 30, 1445-1489.

Blanchard, O. and R. Perotti (2002): "An Empirical Characterization Of The Dynamic Effects Of Changes In Government Spending And Taxes On Output," The Quarterly Journal of Economics, 117, 1329-1368.

Bohn, H. (1998): "The Behavior Of U.S. Public Debt And Deficits," The Quarterly Journal of Economics, 113, 949-963.

Calvo, G. A. (1983): "Staggered price setting in a utility-maximizing framework." Journal of Monetary Economics, 12, 383-398.

Christiano, L. J., M. Eichenbaum, and C. L. Evans (2005): "Nominal Rigidities and the Dynamic Effects of a Shock to Monetary Policy," Journal of Political Economy, 113, $1-45$.

Christiano, L. J., R. Motto, and M. Rostagno (2010): "Financial factors in economic fluctuations," Working Paper Series 1192, European Central Bank.

Christiano, L. J., M. Trabandt, and K. Walentin (2011): "Introducing financial frictions and unemployment into a small open economy model," Journal of Economic Dynamics and Control, 35, 1999 - 2041.

Del Negro, M. And F. Schorfheide (2008): "Forming priors for DSGE models (and how it affects the assessment of nominal rigidities)," Journal of Monetary Economics, 55, 1191-1208.

Erceg, C. J., D. W. Henderson, And A. T. Levin (2000): "Optimal monetary policy with staggered wage and price contracts," Journal of Monetary Economics, 46, 281-313.

Favero, C. And T. Monacelli (2005): "Fiscal Policy Rules and Regime (In)Stability: Evidence from the U.S," Working Papers 282, IGIER (Innocenzo Gasparini Institute for Economic Research), Bocconi University. 
Fernández-Villaverde, J., P. A. Guerrón-Quintana, K. Kuester, And J. Rubio-Ramírez (2011): "Fiscal Volatility Shocks and Economic Activity," NBER Working Papers 17317, National Bureau of Economic Research, Inc.

Forni, L., L. Monteforte, And L. Sessa (2009): "The general equilibrium effects of fiscal policy: Estimates for the Euro area," Journal of Public Economics, 93, 559-585.

GEWEKE, J. (1999): "Using simulation methods for bayesian econometric models: inference, development,and communication," Econometric Reviews, 18, 1-73.

Iskrev, N. (2010): "Local identification in DSGE models," Journal of Monetary Economics, 57, 189-202.

Jones, J. B. (2002): "Has fiscal policy helped stabilize the postwar U.S. economy?" Journal of Monetary Economics, 49, 709-746.

JudD, K. L. (2002): "Capital-Income Taxation with Imperfect Competition," American Economic Review, 92, 417-421.

Kirsanova, T., M. Satchi, D. Vines, and S. Wren-Lewis (2007): "Optimal Fiscal Policy Rules in a Monetary Union," Journal of Money, Credit and Banking, 39, 1759-1784.

LEEPER, E. M. (1991): "Equilibria under 'active' and 'passive' monetary and fiscal policies," Journal of Monetary Economics, 27, 129-147.

Leeper, E. M., M. Plante, and N. Traum (2010a): "Dynamics of fiscal financing in the United States," Journal of Econometrics, 156, 304-321.

Leeper, E. M., A. W. Richter, and T. B. Walker (2010b): "Quantitative Effects of Fiscal Foresight," NBER Working Papers 16363, National Bureau of Economic Research, Inc.

Schmitt-Grohé, S. And M. Uribe (2004): "Optimal fiscal and monetary policy under sticky prices," Journal of Economic Theory, 114, 198-230.

(2006): "Optimal Fiscal and Monetary Policy in a Medium-Scale Macroeconomic Model," in NBER Macroeconomics Annual 2005, Volume 20, National Bureau of Economic Research, Inc., NBER Chapters, 383-462.

- (2007): "Optimal simple and implementable monetary and fiscal rules," Journal of Monetary Economics, 54, 1702-1725.

Sims, C. A. (2003): "Probability Models for Monetary Policy Decisions," Mimeo, Princeton University.

Smets, F. And R. Wouters (2007): "Shocks and Frictions in US Business Cycles: A Bayesian DSGE Approach," American Economic Review, 97, 586-606.

TAYLOR, J. B. (1993): "Discretion versus policy rules in practice," Carnegie-Rochester Conference Series on Public Policy, 39, 195-214. 
(2000): "Reassessing Discretionary Fiscal Policy," Journal of Economic Perspectives, $14,21-36$.

Trabandt, M. And H. Uhlig (2011): "The Laffer curve revisited," Journal of Monetary Economics, 58, $305-327$.

Traum, N. And S.-C. Yang (2010): "When Does Government Debt Crowd Out Investment?" Caepr Working Papers 2010-006, Center for Applied Economics and Policy Research, Economics Department, Indiana University Bloomington.

Traum, N. And S.-C. S. Yang (2011): "Monetary and fiscal policy interactions in the post-war U.S," European Economic Review, 55, 140-164.

Woodford, M. (2003): Interest and Prices: Foundations of a Theory of Monetary Policy, Princeton University Press. 